Board of Governors of the Federal Reserve System

International Finance Discussion Papers

Number 594

October 1997

\title{
A NONLINEAR ECONOMETRIC ANALYSIS OF CAPITAL FLIGHT
}

\author{
Lisa M. Schineller
}

NOTE: International Finance Discussion Papers are preliminary materials circulated to stimulate discussion and critical comment. References in publications to International Finance Discussion Papers (other than an acknowledgment that the writer has had access to unpublished material) should be cleared with the author or authors. Recent IFDPs are available on the Web at www.bog.frb.fed.us. 


\title{
A NONLINEAR ECONOMETRIC ANALYSIS \\ OF CAPITAL FLIGHT
}

Lisa M. Schineller*

\begin{abstract}
This paper develops a nonlinear econometric model of the determinants of capital flight for eighteen developing countries over the period 1978 to 1988. During most of the 1980s, capital flight proved difficult to reverse. Besides an uncertain domestic policy environment, costs associated with such an investment decision might have delayed flight reversal. Costs that characterize flight reversal could generate potentially significant barriers to continual adjustment of an investment position. This in turn would generate a nonlinear relationship between flight and its determinants, which reflect the degree of domestic macroeconomic imbalance. To detect the existence, and importance, of cost-driven thresholds we model flight within the context of a friction, or two-threshold Tobit, model. Given the panel data set, we consider a country-specific error component to account for the possibility of unobserved countryspecific heterogeneity. To correct for endogeneity among the regressors in the random-effects nonlinear estimation, we implement Newey (1987). While the data seemingly do not support the existence of costdriven thresholds for flight, the central government surplus, premium for foreign exchange in the black market and the presence of an IMF adjustment program are all significantly related to flight. The negative relationship between fiscal balances and flight highlights the desire by investors to escape future taxation directly, and indirectly via monetization of fiscal deficits, by undertaking capital flight. In devising a framework for reform, that typically entails fiscal consolidation, IMF supervision, endorsement and surveillance lend credibility to reform and reassure investors.
\end{abstract}

Keywords: capital flight, macroeconomic risk, panel data, two-threshold Tobit model

* The author is an economist in the Division of International Finance, Board of Governors of the Federal Reserve System and this paper is based on dissertation research at Yale University. I would like to thank Willem H. Buiter, Nouriel Roubini, T.N. Srinivasan, Vassilis Hajivassiliou, Mico Loretan, Paolo Pesenti, Brian Fikkert and Eric Larsen for helpful comments and discussions. The views in this paper are solely the responsibility of the author and should not be interpreted as reflecting the views of the Board of Governors of the Federal Reserve System or of any other person associated with the Federal Reserve System. 
This paper develops a nonlinear econometric model of the determinants of capital flight and in so doing differs significantly from other empirical analyses of flight. Capital flight, or international capital movements which respond to heightened domestic economic and political uncertainty, affected many developing nations during the 1980 s and proved difficult to reverse during that time period. We aim to determine whether irreversibilities, in addition to domestic policy actions, contributed to a postponement of flight reversal.

Despite the negative connotation associated with the term capital flight, its impact on an economy is ambiguous. Indeed, only when its potentially detrimental effects are borne out during a crisis do economists, policy makers, politicians, bankers, and investors consider its possible adverse effects on an economy, or potential for systemic contagion. Its disruptive effects on domestic investment, the foreign exchange market, public finances and in turn domestic economic activity become more severe, and more likely, as the magnitude of flight increases. For some developing countries, flight approached or exceeded ten percent of GNP during the 1980s, representing a substantial outflow of resources. Furthermore, the longer flight capital remains abroad, the worse are the consequences for economic activity, especially in a developing economy that is dependent on external financing.

Capital flight responds to the degree of domestic macroeconomic mismanagement, postulated to generate a domestically undiversifiable risk that can significantly reduce the returns on local investment. Although forever present, uncertainty about domestic macroeconomic policy might not prompt capital flight or flight reversal in a continuous manner. Anecdotal evidence suggests that a dramatic deterioration or improvement in the domestic investment climate tends to underpin flight and flight reversal. Depending on the underlying fundamentals, this might reflect the fact there are costs associated with changing one's flight position. The existence of potentially significant adjustment costs implies a non-continuous adjustment between flight and flight reversal, and a nonlinear relationship between capital flight and its determinants. Capital flight might occur only when its determinants, namely measures of domestic policy 
risk, exceed some high-risk, or upper, threshold. Flight reversal might occur only when such risk recedes below some low-risk, or lower, threshold. To test for such a nonlinear relationship, we estimated a twothreshold Tobit model. The model explicitly incorporates the notion that thresholds must be surpassed for flight and flight reversal to be observed.

The paper first discusses the estimates and cross-country patterns of capital flight for the sample of eighteen developing countries from 1978 to $1988 .{ }^{1}$ A comparison between the observed patterns of flight and anecdotal evidence on domestic macroeconomic policy conditions motivates the determinants of flight in the econometric model. The paper includes a detailed discussion of the dependent variable, capital flight, and of the estimation techniques that we employed. Given the panel-data set, we model the error term to account for the possibility of unobserved country-specific heterogeneity, and the results suggest that it is important to model such heterogeneity. To correct for endogeneity among the explanatory variables, we implement Newey (1987) given the nonlinear model specification. While the data seemingly do not support the existence of cost-driven thresholds for flight, we found the central government surplus, premium for foreign exchange in the black market and presence of an IMF austerity program to be statistically significantly related to capital flight. The strength of the results on the fiscal position in particular highlights the important link between capital flight and the desire to escape future taxation directly and indirectly via the monetization of fiscal deficits. Also, IMF supervision, endorsement and surveillance of domestic reform, that typically entails fiscal consolidation, lend credibility to reform and reassure investors.

\section{$2 \quad$ Estimates of capital flight}

Capital flight statistics are not readily available, instead they must be constructed. Since there is no universal definition of capital flight, the literature offers several different approaches for devising flight estimates. $^{2}$ The estimates presented in this paper are based on the residual approach, which is premised on circumventing the use of "unreliable" balance of payments capital account data to calculate flight indirectly. The residual approach posits that the recorded increase in gross foreign debt provides a better 
measure of net foreign loans, foreign loans less amortization, than do balance of payments data. There are several ways to calculate flight according to this approach which generates a broad measure of flight. ${ }^{3}$

Of the several residual measures, the capital flight statistics we employ are based on the World Bank (1985) definition. The approach is premised on trying to identify both the sources and uses of international funds by a nation. Source funds consist of the increase in recorded gross external debt and net foreign direct investment, which can in turn be used to finance the current account and/or to increase official reserves. In effect, the World Bank definition equates capital flight with all non-official capital outflows and the change in a nation's foreign asset position.

All empirical measures of capital flight are subject to criticism, and, while employing it, we acknowledge that there are difficulties are associated with the World Bank definition. First, the magnitude of flight varies with the accuracy and comprehensiveness of debt coverage. The debt component suffers from valuation effects as the U.S. dollar fluctuates. Second, this measure, as do all the other measures in the literature, fails to capture flight associated with trade mis-invoicing. Third, since it does not distinguish between normal and super-normal non-official portfolio movements, the measure overestimates flight by the amount of normal portfolio movements that stem from differences in tastes, technology and endowments, and capital movements that are associated with trade transactions. Hence, it is more appropriate to focus on the relative magnitudes of the flight estimates and how they change over time, and not specific flight estimates.

\section{Cross country comparisons}

We conclude that domestic policy underpins the motive to engage in capital flight, and flight reversal. Similar macroeconomic imbalances seem to have characterized those nations who underwent pronounced capital flight episodes. As the estimates of capital flight in Chart 1 and Tables 1 and 2 reveal, the eighteen developing nations in our sample experienced different degrees of capital flight, and flight reversal, between 1978 and 1988. On a GNP-weighted basis, capital flight averaged about 1.6 percent of GNP through 1984 and accelerated to an average 2.0 percent of GNP from 1985 to 1988 . The overall 
pattern of flight and flight reversal diverges for Latin and non-Latin American countries. Flight was more pronounced from Latin America during the late 1970s and early 1980s. Between 1978-1984, flight from Latin America averaged 2.2 percent of GNP, compared with 1.0 percent of GNP for Asia. While the pace of flight slowed on average to 1.5 percent of GNP for Latin nations during 1985 and 1988, that from Asia picked-up to 2.5 percent of GNP. Although we do not quantify it, some of the acceleration in Asian flight likely reflects a statistical artifact, namely the tendency for U.S. dollar depreciation that began in 1985 to raise the value of non-dollar denominated external debt in U.S.-dollar terms; this in turn inflates the source funds available to finance capital flight. Flight moderated somewhat at the very end of the sample period which ends in 1988. These data only capture the very beginning of the global shift in capital flows to emerging markets from capital flight, to a cessation of flight, to pronounced capital inflows in the 1990s, owing in part to capital flight reversal.

A comparison of the anecdotal evidence on country-by-country macroeconomic policy and our estimates of capital flight confirms that pronounced flight occurred when a nation experienced severe macroeconomic imbalances. A combination of large fiscal deficits, overvalued exchange rates, high and/or volatile inflation, and ambitious financial sector liberalization seemed to generate flight in many nations. Political instability and domestic unrest, which was sometimes, but not necessarily related to the economic situation, also prompted flight. We posit that flight occurred as the risk associated with local investment, due to mismanaged domestic policy, became relatively high, and as the risk premia associated with expected domestic returns failed to adequately reflect the potential for losses. Anecdotal evidence also seems to indicate that if an inconsistent policy mix and/or political unrest co-existed with few capital account restrictions, more flight probably occurred than had the capital account been closed (effectively). We draw this conclusion after considering the underlying economic fundamentals and the both the magnitude of flight from and relatively open capital accounts of Mexico, Argentina, Venezuela, Indonesia and Malaysia compared with the combination of less pronounced flight and tighter controls in Brazil, Colombia, India and Korea. 
Estimates of flight estimates after 1988 suggest that capital inflows, in general, have been accompanied by sustained macroeconomic stabilization and structural adjustment programs, as well as lower asset returns in industrialized nations. Flight only reversed on a sustained basis after nations committed to deficit reduction, exchange rate adjustment, trade liberalization and privatization. Importantly, it seems that only after reform was not short-lived and/or was perceived as credible did significant capital flight reversal occur. Until credible, sustainable stabilization is implemented, cautious investors will either maintain or only marginally reverse flight keeping funds poised for reinvestment abroad.

The difficulties associated with enticing flight reversal might stem from the combination of and interaction of uncertain, non-credible stabilization and any costs that are associated with flight reversal. In general the data indicate that a very large capital outflow in one year does not tend to be followed by capital inflow of a similar magnitude in the next time period. In most instances, after flight occurs, it is succeeded first by a period of more subdued capital flows, and then flight reversal, or renewed flight. Depending on the underlying macroeconomic fundamentals, the period of moderate capital flows may reflect the presence of adjustment costs. Irreversibilities may exacerbate and contribute importantly to a "wait and see" attitude among investors.

\section{$4 \quad$ The determinants of flight}

In modelling the determinants of capital flight, the paper uses Dooley (1988) as a starting point, and served as the basis for Schineller (1997), an updated, linear panel-data analysis. ${ }^{4}$ Dooley (1988) incorporates the notion that domestic and foreign investors face asymmetric risk when investing in a developing economy; such risk asymmetry determines the magnitude of capital flight. ${ }^{5}$ We propose that risk associated with domestic policy mismanagement underpins flight and that this risk may, but need not, be asymmetric. The paper goes beyond relying on traditionally measured rates of return to capture the relationship between pervasive, domestic policy risk and capital flight. In contrast, Cuddington (1986) takes a narrow, conventional rate of return approach. ${ }^{6}$ Meanwhile, Varman (1989) uses econometric 
modelling to quantify the magnitude of capital flight, not its determinants; flight is the fraction of gross capital outflows motivated by the discriminatory treatment of domestic capital, political upheaval, and uncertainty. ${ }^{7}$

The regressors in the nonlinear model reflect the need for macroeconomic adjustment. In other econometric work, we also considered alternative proxies of the need for macroeconomic adjustment, such as the level and volatility of inflation, without success. Since no internally consistent, comprehensive index of political stability or political risk coincides with the sample period, we had tried to capture political instability with a variable that summarized turnover in the executive branch of the government. The conceptual difficulties associated with the measure and the fact it failed to be statistically significant, led us to exclude them from this analysis. ${ }^{8}$

A conventional indicator of the risk between domestic and foreign assets is the differential in domestic and foreign interest rates adjusted for expected depreciation of the exchange rate; both Cuddington (1986) and Dooley (1988) consider this variable. We calculate this risk premium as the difference between domestic short-term commercial bank deposit rates and the U.S. Treasury Bill rate, adjusted for actual depreciation of the official exchange rate in U.S. dollar terms. Since many domestic financial markets were and remain in the earlier stages of development, the use of such deposit rates seemed appropriate. We expect a negative relationship between this interest rate differential and the dependent variable, capital flight.

If domestic and foreign assets are not perfect substitutes, as expected, the risk premium will not be zero and the rate of return differential should capture both default and country risk. However, often domestic asset returns are not fully market determined; financial repression characterizes many developing financial markets. Under these circumstances, the rate of return differential will not fully reflect the risks associated with domestic vis-a-vis foreign investment. Thus, we include other measures of risk in the econometric analysis.

A large fiscal deficit potentially signals fiscal mismanagement and/or macroeconomic instability. 
The need for future fiscal adjustment, be it through formal taxation or inflationary financing, clearly reflects the risks associated with domestic policy. Given that we could not obtain data on the consolidated public sector's fiscal position, we include the central government surplus as a share of GNP as an explanatory variable. We anticipate a negative relationship between the government surplus and flight.

The premium for foreign exchange in the black market serves as another indication of the risk associated with domestic investment. When official exchange rates are not market determined and there are restrictions on capital flows, the black market premium often reflects the market's perception of domestic policy sustainability. Suppose domestic credit expands; a fixed official exchange rate remains constant while a freely floating black market rate depreciates. The black market premium reflects an inconsistent policy mix and portends a possible devaluation of the official rate; the implied losses on domestic assets prompts agents to engage in flight. We define the black market premium as the ratio of the black market exchange rate to the official exchange rate and expect a positive relationship with flight. ${ }^{9}$

In general, the economies of nations experiencing capital flight are in a state of crisis and must implement a stabilization program to contain the crisis. An IMF program may lend credibility to the reform effort and restore confidence in the domestic economy since it imposes external discipline and is often accompanied by renewed foreign financing and agreements on debt rescheduling. We anticipate that the imposition of an IMF stabilization program would diminish the risk associated with domestic investment. We include a zero-one dummy variable that assumes a value of one when a nation had an IMF agreement in place in a given year; we expect it to exhibit a negative relationship with flight.

Restrictions on international capital mobility most probably will affect the feasibility of undertaking flight, and the relative magnitude of flight across nations. To control for restrictions on capital flows, we include a dummy variable that assumes a value of one when capital controls were in place (otherwise zero). We anticipate a negative relationship between the presence of capital controls and flight. $^{10}$

\section{Econometric model and estimation methodology}


In estimating a nonlinear panel-data model specification, this paper differs significantly from other econometric analyses of flight. Other studies employ linear time-series techniques, such as Cuddington (1986) and Varman (1989), or linear panel-data techniques, such as Dooley (1988) and Schineller (1997). The objective of this paper is not only to model the determinants of capital flight, but also to ascertain whether the decision to engage in capital flight is nonlinear. To determine whether flight and flight reversal are affected by barriers to continual portfolio adjustment, this paper considers a friction model. In their classic application, friction models are employed to account for the impact of transaction costs on portfolio asset allocation. Should irreversibilities characterize the decision to engage in flight, such a model would capture the notion that flight and flight reversal respond to a more extreme deterioration or improvement in the domestic investment climate.

The limited-dependent, time-series, cross-section model we estimate distinguishes between "desired" and "actual" changes in a nation's investment position, or in flight and flight reversal. Due to the presence of adjustment costs, not all "desired" flight is realized and one does not observe directly "desired" flight. "Desired" flight or flight reversal $\mathrm{y}_{\mathrm{it}}{ }^{*}$ satisfies

$$
\begin{array}{r}
\mathrm{y}_{\mathrm{it}}{ }^{*}=\mathrm{x}_{\mathrm{it}}{ }^{\prime} \beta+\varepsilon_{\mathrm{it}}, \\
\mathrm{i}=1, \ldots, \mathrm{N}, \\
\mathrm{t}=1, \ldots, \mathrm{T},
\end{array}
$$

for country $i$ at time $t$. However, one only observes "actual" flight $\mathrm{y}_{\mathrm{it}}$ such that

$$
\mathrm{y}_{\mathrm{it}}=\tau\left(\mathrm{y}_{\mathrm{it}}^{*}\right) \text {. }
$$

The function $\tau(\cdot)$ specifies the nonlinear rule that relates the unobserved latent variable $\mathrm{y}_{\mathrm{it}}{ }^{*}$ to the observed $\mathrm{y}_{\mathrm{it}}$. As in the classic friction model, we employ a two-threshold Tobit specification where $\tau(\cdot)$ satisfies:

$$
\begin{array}{ll}
\tau(\cdot): \quad y_{i t}=y_{i t}^{*} \quad \text { if } \quad y_{i t}^{*}<c^{1}, \\
y_{i t}=0 \quad \text { if } \quad c^{1} \leq y_{i t}^{*} \leq c^{h}, \\
y_{i t}=y_{i t}^{*} \quad \text { if } \quad y_{i t}^{*}>c^{\mathrm{h}} .
\end{array}
$$

There is both an upper and a lower threshold, $\mathrm{c}^{\mathrm{h}}$ and $\mathrm{c}^{\mathrm{l}}$, for observed adjustments in a nation's international investment position which differ and are not symmetric about zero. Only when the magnitude of "desired" 
flight, in the absence of adjustment costs, exceeds the upper or lower threshold, $c^{\mathrm{h}}$ or $\mathrm{c}^{1}$, do we observe flight, or flight reversal.

When the dependent variable is censored, performing Ordinary Least Squares (OLS) on the observed $\mathrm{y}_{\mathrm{it}} \mathrm{s}$ yields biased and inconsistent parameter estimates. Applying Maximum Likelihood Estimation (MLE) to the appropriate likelihood function exploits the information contained in the distribution of the unobserved $\mathrm{y}_{\mathrm{it}}$ and produces consistent and asymptotically efficient parameter estimates. We consider two likelihood functions for the Tobit model based on alternative assumptions about the error-term specification; one is homogeneous across nations and the other permits heterogeneity across nations. Appendix 1 details the different likelihood functions.

First, we consider an error-term $\varepsilon_{\text {it }}$ that is a serially uncorrelated and homoscedastic for each country $i$ such that:

$$
\varepsilon_{\mathrm{it}} \sim \text { iid } \mathrm{N}\left(0, \sigma^{2}\right) \text {. }
$$

MLE yields consistent and asymptotically efficient parameter estimates of $\beta$ and $\sigma$, assuming $\mathrm{E}\left(\varepsilon_{\mathrm{it}} \mid \mathrm{x}_{\mathrm{i} t}\right)=0$. With panel-data, however, it is usually inappropriate to assume that the error-term $\varepsilon_{\mathrm{it}}$ satisfies equation (4). Countries have different histories and political and financial institutions that likely affect the decision to undertake capital flight. This generates heterogeneity in the error-term structure across nations. To control for possible country-specific effects, we model unobserved, persistent country-specific heterogeneity with a one-factor random-error components model:

$$
\varepsilon_{\mathrm{it}}=\eta_{\mathrm{i}}+v_{\mathrm{it}},
$$

where

$$
\eta_{\mathrm{i}} \sim \operatorname{iid} \mathrm{N}\left(0, \sigma_{\eta}^{2}\right)
$$

and

$$
v_{\text {it }} \sim \operatorname{iid} \mathrm{N}\left(0, \sigma_{v}^{2}\right) \text {. }
$$

The persistent, unobserved heterogeneity, $\eta_{\mathrm{i}}$, introduces serial correlation within each country's error structure and generates a non-scalar variance-covariance matrix. In nonlinear, time-series, crosssection models, this serial correlation yields parameter estimates that are not only inefficient, but also biased and inconsistent. This "incidental parameters problem" is typically resolved by employing fixed- 
effects or random-effects estimation. Given the desire to generalize about the relationship between flight and its determinants beyond the sample, we postulate a random-error structure as in equation (5). We then integrate over the random-error component $\eta_{\mathrm{i}}$ for each individual nation's conditional likelihood function in order to obtain consistent and asymptotically efficient estimates of $\beta$ and $\Sigma_{\varepsilon}$, assuming $E\left(\eta_{i} \mid x_{i t}\right)=0$ and $\mathrm{E}\left(\mathrm{v}_{\mathrm{it}} \mid \mathrm{x}_{\mathrm{it}}\right)=0$.

The consistency of the parameter estimates under the error-term specification of equation (4) or (5) requires that there be no simultaneity between flight and its regressors. We propose that the black market premium and the government surplus-to-GNP ratio violate the assumption that $\mathrm{E}\left(\varepsilon_{\mathrm{it}} \mid \mathrm{x}_{\mathrm{it}}\right)=0$ or $\mathrm{E}\left(v_{\mathrm{it}} \mid \mathrm{x}_{\mathrm{it}}\right)=0 .{ }^{11}$ The black market rate is the relevant exchange rate for many international transactions including capital outflows, especially when such flows are restricted, and thus may be affected by flight. Meanwhile, as a measure of policy risk, the black market premium may prompt flight. ${ }^{12}$ Under a sourcebased system of taxation, flight adversely affects government revenues, and may exacerbate the government deficit. At the same time, large deficits signal fiscal mismanagement, and prompt flight. ${ }^{13}$

To obtain consistent parameter estimates, we instrument for these variables employing Newey (1987). Newey formalizes a consistent and asymptotically efficient estimation technique for estimating the parameters of limited-dependent variable, or nonlinear, models that have endogenous, linear explanatory variables. The Newey methodology entails performing several estimations on the system of simultaneous equations. When first estimating the nonlinear, reduced-form expression for capital flight the regressors include the residuals from reduced-form, linear estimation of the endogenous explanatory variables. By applying Amemiya (1978) Generalized Least Squares (AGLS) to the resulting nonlinear reduced-form parameter estimates, one obtains an efficient estimate of $\beta$. However, to recover an efficient estimate of $\sigma$ or $\sigma_{\eta}$ and $\sigma_{v}$, we then employ a modified Minimum Chi-Square (MCS) technique. ${ }^{14}$

\section{$5 \quad$ Adjusting measured capital flight estimates for Tobit estimation}

The two-threshold Tobit model is a limited-dependent variable model in which the dependent variable assumes either a specific magnitude or a value of zero: $\mathrm{y}_{\mathrm{it}}=\mathrm{y}_{\mathrm{it}}{ }^{*}$ or $\mathrm{y}_{\mathrm{it}}=0$. However, the capital 
flight statistics in Tables 1 and 2 are not censored in such a manner. In order to test whether flight is affected by adjustment costs and that macroeconomic policy risk must surpass certain threshold levels to prompt flight, we censor the capital flight estimates. In doing so, we attempt to isolate the capital movements that are extreme in magnitude.

As noted in Section 2, the capital flight data used in this paper are based on the World Bank definition. Since this measure of flight captures all non-official capital flows, it includes normal portfolio and trade-related non-flight capital flows. To distinguish between flight and non-flight capital flows, we appeal to the notion that capital flight is subject to irreversibilities which in turn requires domestic policy risk to surpass some critical threshold level. Due to the requisite realization of underlying policy fundamentals to overcome adjustment costs, we assume that flight is likely to be relatively large in magnitude, and that it is not optimal to engage in flight incrementally. We also assume that the non-flight flows representing continual portfolio adjustment or trade-related transactions are generally relatively small in magnitude. Such flows need not respond to a large, coordinating domestic policy shock, and are not affected by adjustment costs.

We approximate the smaller, non-flight capital flows with a values of zero. In the process of determining whether a capital flow is "small", we consider the positive and negative capital flows separately. There is no reason to expect that flight and flight reversal decisions are symmetric. Theoretically, the adjustment costs need not be symmetric and hence the upper and lower thresholds, $\mathrm{c}^{\mathrm{h}}$ and $c^{1}$, in the empirical model need not be symmetric around zero. Accordingly, we do not impose symmetry upon the data.

In deriving a censored flight series, we might actually set a capital flow to zero that should be classified as capital flight, but appears "small" due to measurement error. Thus, we calculate several different measures of censored flight that correspond to the sample's 20th, 25th and 30th percentiles to compare the resulting parameter estimates. ${ }^{15}$ For example, we set the capital flow as a share of GNP-- ${ }_{\text {it }}{ }^{-}$ - for country $i$ at time $t$ equal to zero if it falls within the sample's lowest $20 t h$ percentile. As noted, the 
20th percentile of the positive and negative flows as a share of GNP are calculated separately. We generate a limited dependent variable that equates observed flight and flight reversal, $\mathrm{y}_{\mathrm{it}}=\mathrm{y}_{\mathrm{it}}$ *, with those capital flows that fall outside the sample's 20th percentile. Unobserved, or non-flight, flows are those capital flows that are within the sample's 20th percentile; $\mathrm{y}_{\mathrm{it}}=0$.

\section{$7 \quad$ Empirical Results}

Having generated a censored capital flight series, we can estimate the two-threshold Tobit model

to determine whether flight requires extreme magnitudes of macroeconomic policy risk in order to overcome adjustment costs--and whether a friction, or two-threshold Tobit, model captures this phenomenon. Newey-based parameter estimates for the two-threshold Tobit model under the homogeneous and heterogenous error-term structures appear in Tables 3 and 4, respectively. The parameter estimates under the homogeneous error-term assumption (for $\beta$ and $\sigma$ ) reflect the AGLS-MCS estimation procedure outlined in Section 5. However, when estimating the heterogeneous error-term model, it was not feasible to estimate simultaneously all the parameters of the model $\left(\beta, \sigma_{\eta}, \sigma_{v}\right)$. Insufficient variation in the data may have precluded the identification of $\sigma_{\eta}$ and $\sigma_{v}$ along with coefficient estimates of the regressors, $\beta$. The only feasible way of estimating the model with random-effects was to estimate $\beta$ holding $\sigma_{\eta}$ and $\sigma_{v}$ fixed, or estimate $\sigma_{\eta}$ and $\sigma_{v}$ holding $\beta$ fixed. Hence, the parameter estimates for $\beta$ in Table 5 reflect limited information, or conditional, AGLS after several iterations.

As discussed in the previous section, we present parameter estimates for the two-threshold Tobit model based on three alternative censored capital flight measures. Since the likelihood function for the two-threshold Tobit is monotonically increasing in both threshold $\mathrm{c}^{\mathrm{h}}$ and threshold $\mathrm{c}^{1}$, it is not possible to estimate these thresholds. Thus, when estimating the model, we must hold as fixed the values for the thresholds $c^{h}$ and $c^{1}$ at the appropriate values implied by the distribution of $y_{i t}{ }^{*}$ for the entire sample. These correspond to the values of capital flight associated with the sample's 20th, 25th and 30th percentiles and are noted on Tables 3 and 4. Also, it is not feasible to impose meaningful, heterogeneous thresholds across nations since the time-series dimension of the panel data set is eleven years. This should 
not introduce a serious source of mis-specification error under the heterogeneous error-term structure; the country-specific error-component $\eta_{i}$ should account for cross-country differences in the underlying costs associated with flight and flight reversal.

The Newey-based determinants of capital flight in Tables 3 and 4 are robust to both the homogeneous and heterogeneous error-term structure and the three different measures of censored flight. As expected, the central government surplus and presence of an IMF adjustment program, are negatively, statistically significantly related to flight. The model consistently suggests that a deteriorating fiscal position corresponds with increased capital flight. This highlights the motivation of investors to move capital abroad both to escape future taxation directly and indirectly via monetization of deficits. The commitment to reform macroeconomic imbalances by implementing an IMF adjustment program--that typically entails fiscal deficit reduction--is associated with flight reversal. IMF supervision, endorsement and surveillance of a stabilization program, that are devoid of political preference, lend credibility to the reform process and reassures investors.

Surprisingly, the coefficient for the black market premium is also negative and statistically significant. This result does not support the proposition that a larger premium portends an official devaluation with capital losses on domestic assets, that in turn increases the incentive to undertake capital flight. Since black markets are often thin, the black market exchange rates may be noisy; this in turn would affect the reliability of our results. Alternatively, for the premium to reflect the likelihood of an official devaluation, there must be both a (semi) fixed official rate that has not been (fully) adjusted to reflect underlying economic fundamentals and the presence of restrictions on capital movements. With an open capital account and floating official exchange rate, flight can respond to macroeconomic imbalances that are not captured by the differential between official and black market rates. Anecdotal evidence for several countries indicates that this is a possible explanation for our results. ${ }^{16}$

The other regressors, the differential in interest rates adjusted for actual depreciation of the exchange rate and proxy for capital controls, are statistically insignificant. Although insignificant, the 
interest rate differential, adjusted for actual depreciation, exhibits an unanticipated positive relationship with flight. Since we consider actual, not expected, depreciation, the results are vulnerable to the "peso problem" in which agents may anticipate a depreciation of the domestic currency that does not materialize ex-post. Agents might have engaged in flight based on an expected differential that is not captured by our data. ${ }^{17}$ Alternatively, as a risk premium, this differential may indeed be detecting a higher degree of risk in the domestic economy. Should the magnitude of the risk premium not compensate investors for domestic risk, agents would instead engage in flight generating a positive relationship between flight and this risk premium. The capital control variable does not exhibit the expected negative relationship with flight. We attribute this to the fact that this measure does not reflect the intensity of capital account restrictions.

Evidence to support the modelled determinants of capital flight taken as a whole is mixed. We cannot calculate a goodness-of-fit measure and conduct a likelihood ratio test premised on the Neweybased procedure. It is not possible to compute the value of the log-likelihood function associated with its parameter values. However, once can assess the robustness of the models based on Blundell and Smith's (1986) Two Stage Instrumental Variable (2SIV) methodology. This approach yields parameter estimates that are consistent, but not asymptotically efficient--in contrast with the efficient Newey estimates. Conveniently, their 2SIV estimation serves as an auxiliary regression for the Newey-based estimates (as footnoted and detailed in Appendix 2).

The log-likelihood values and likelihood-ratio test statistics In Tables 3 and 4 are calculated from the 2SIV technique. For the homogeneous error-term model, the likelihood-ratio test indicates that the data do reject the null hypothesis, that variations in the dependent variable are due to chance alone. This suggests that the consistent, efficient AGLS-MCS approach supports the model of flight. However, the 2SIV regressions that underpin the constrained-AGLS estimates of the country-specific heterogenous errorterm model suggest that the model is not robust. When allowing for random-effects in the auxiliary estimations, the data do not reject the null hypothesis; this suggests that, as a group, the regressors do not 
capture the motivation for flight. It is possible that the overall explanatory power of the regressors is undermined by fact we cannot estimate simultaneously $\beta, \sigma_{\eta}$ and $\sigma_{v}$.

While suggesting that with a country-specific error term, the model of flight is not robust, this result does suggest that it is important to model capital flight with a heterogenous error component. The importance of the country-specific error term apparently dominates the modelled determinants of flight--as a group. Unlike in linear panel-data estimations, we cannot definitively test for the presence of a countryspecific error component in the two-threshold Tobit model. However, additional evidence suggests that the random-effects model is the more appropriate model to estimate. The 2SIV log-likelihood values are slightly higher for the model with the country-specific error component. More importantly, both the heterogeneous and iid error components are always statistically significant. Finally, in a comparable linear estimation, the Breusch-Pagan specification test does detect presence of country-specific heterogeneity in the data.

We employ the Newey methodology to correct for proposed simultaneity between flight, the black market premium and the government surplus. As suggested by Newey (1987), we perform an exogeneity test on the estimation results to assess this proposition and construct a likelihood-ratio test to determine whether the coefficients on the black market premium and government surplus residuals are jointly zero. Conveniently, the 2SIV estimates form the basis of this exogeneity test. The data reject the null hypothesis of no simultaneity between these variables with an homogenous error-term. However, with random-effects estimation the data do not reject the null hypothesis that the black market premium and government surplus are exogenous. However, while the residuals for the black market premium are statistically insignificant in this auxiliary regression, those for the government surplus are statistically significant. This suggests that future estimation should instrument for the government surplus alone. The importance of the fiscal position was confirmed once again, when we estimated the model with randomeffects without correcting for any simultaneity; the government surplus was the only statistically significant regressor. 
The two-threshold Tobit model proposes to capture potential nonlinearities associated with the decision to undertake flight, and accordingly the relationship between flight and its regressors. To assess how critical and/or important the nonlinear formulation might be, whether the nonlinear approach reflects the data, we compare the Newey-based nonlinear parameter estimates with parameter estimates from a corresponding linear model. If the true underlying model is nonlinear, the linear estimates would be biased and inconsistent since they are based on a linear estimation of censored capital flight. The two sets of parameter estimates should be sufficiently different if the nonlinear specification and estimation methodology are more appropriate. Tables 5 and 6 present linear panel-data results that are premised on instrumenting for the black market premium and government surplus. While the nonlinear parameter estimates in general tend to exhibit greater statistical significance, the linear coefficients are not distinctly different from the Newey-based coefficients. The nonlinear model does not seem to capture a dramatic difference in how macroeconomic imbalance affects capital flight; if nonlinear barriers to flight do exist, our data and methodology do not seem to be accounting for them.

\section{$8 \quad$ Conclusion}

This paper develops a nonlinear econometric model of capital flight in order to determine whether there exist potentially significant adjustment costs associated with the decision to undertake capital flight and flight reversal. The existence of such costs implies non-continuous adjustment between flight and flight reversal, and a nonlinear relationship between capital flight and its determinants, which reflect the stance of domestic macroeconomic policy risk. Capital flight might occur only when its determinants surpass a critical level or threshold. To this end, we estimate a two-threshold Tobit model for a panel data set of developing nations accounting for both country-specific heterogeneity and potential simultaneity among the regressors.

This nonlinear analysis does not yield definitive empirical support for the proposition that the decision to undertake or reverse capital flight is subject to costs of adjustment. There is not a substantial difference between the estimated coefficients derived from nonlinear and linear methodologies, where the 
former account for the explicit modelling of thresholds. Although there may not be significant barriers to flight and flight reversal, there may be a more appropriate econometric methodology to test for their existence. First, the two-threshold Tobit model relies upon a censored dependent variable. The capital flight data we employ are not inherently censored; we construct a censored measure of flight in order to test the hypothesis. In addition, we employ estimates of flight for a given nation due to the absence of capital flow estimates for individuals. While individual investor's decisions to engage in flight might very well be affected by adjustment costs, aggregation may smooth underlying micro-rigidity, rendering the detection of thresholds more difficult with aggregate data. Furthermore, while this empirical modelling accounts for the existence of thresholds, it does not address all the implications of the assumptions that flight is characterized by hysteresis. An explicit modelling of hysteresis might yield more robust results.

Other evidence in support of the overall model structure is mixed. When estimating the model with an homogeneous error structure, a robustness test validates the proposed model. However, under random-effects estimation of the heterogeneous error structure, we are unable to reject the null hypothesis that variations in the censored flight variable are due to chance alone. With random-effects, the overall model loses explanatory power. This result, however, suggests that it very important to consider a heterogeneous error-term specification. Also, the values of the maximized log-likelihood functions associated with the 2SIV estimates are larger with random-effects estimation than without. Finally, the country-specific error component is always statistically significant.

Under both error-term specifications, certain measures of domestic policy risk are statistically significant. The significance of the negative relationship between flight and the central government surplus highlights that flight is affected by, and potentially driven by, the desire to avoid increased domestic taxation. A commitment to reform macroeconomic imbalances by implementing an IMF adjustment program--that typically entails fiscal consolidation--lends credibility to reform, reassures investors and tends to generate flight reversal. The at first puzzling negative coefficient on the black market foreign exchange premium can be explained by the fact that flight can respond to macroeconomic 
imbalances that are not captured by the differential between official and black market rates under a system of floating exchange rates and an open capital account. Future work should consider alternative determinants of capital flight, such as a credibility index for exchange rate policy and/or a political instability index. 


\section{Notes}

1. The sample includes Argentina, Bolivia, Brazil, Chile, Colombia, Ecuador, Mexico, Peru, Uruguay, Venezuela, India, Indonesia, Korea, Malaysia, the Philippines, Thailand, Turkey and Yugoslavia. These market borrowing nations were chosen based on their overall level of external indebtedness, not necessarily because they encountered debt service problems, and the availability of data for explanatory variables.

2. The balance of payments approach, as its name suggests, uses capital account data to measure capital flows. While the errors and omissions component of balance of payments statistics do not exclusively represent unreported capital flows, the literature generally accepts their being primarily unreported capital flows. Employing this methodology, Cuddington (1986) defines flight as short-term speculative outflows by the non-bank private sector, or "hot money". He quantifies flight as short-term capital outflows and errors and omissions, which he equates with unreported short-term capital movements.

A second approach relies on data on cross-border bank deposits. The IMF and BIS publish such data on a country-by-country basis. Since they exclude all non bank-deposit investment vehicles, these statistics generate a relatively narrow measure of capital flight. However, since they are a direct measure of reported foreign asset accumulation, they may be subject to less measurement error.

3. Dooley (1988) presents another variation of the residual approach which attempts to distinguish between so called normal and flight capital flows. According to Dooley, flight stems from the desire to avoid domestic taxation. As such, flight need not be a current transaction, but merely reflect a change in the motive for holding a previously acquired foreign asset as the domestic investment climate changes. He defines flight as that stock of foreign assets whose returns have not been reported as investment income in balance of payments statistics. Should all capital outflows and investment income on them be reported, there would be no capital flight under Dooley's approach.

Schineller (1997) employed a Modified World Bank approach that combined both the World Bank and Dooley methodologies and was based upon, but a variant of Claessens and Naude (1993), discussed below. A detailed comparison of the World Bank and Dooley measures reveals that besides the stock versus flow measurement, the key conceptual and empirical distinction between them lies in Dooley's attempt to differentiate all capital outflows from flight flows, where flight is driven by tax avoidance. The Modified-World Bank measure offers an easy way to calculate Dooley flows--capital flight flows broadly defined to encompasses both short-term and long-term non-official capital outflows (the World Bank measure) less any capital outflow that corresponds with a desire to avoid domestic taxation.

Claessens and Naude (1993) make further conceptual adjustments to the World Bank and Dooley methodologies. When using the change in external debt, they partially adjust for the effect of cross currency exchange rate fluctuations and debt forgiveness. More important conceptually, they modify how "source" funds are defined in both approaches. First they define external debt inclusive of short-term and IMF debt, but exclusive of private, non-guaranteed debt, so capital inflows are restricted to net official inflows or increases in net external indebtedness of the public sector. Second, they augment net foreign direct investment with net purchases of corporate equities, which are considered part of flight in many other contexts.

As a result of these, in essence, conceptual adjustments, the Claessens and Naude flight estimates are lower than if one used total (official and non-official) inflows or the change in total external debt. The authors define external indebtedness in this manner to derive net private external claims. They argue that private external indebtedness represents an actual liability of the private sector (expected to be serviced and repaid by the private sector) and do not deem it appropriate to consider the simultaneous, private acquisition of a foreign asset and foreign liability as capital flight. 
4. Schineller (1997) analyzes capital flight from a group of seventeen developing nations from Latin America and Asia over the period 1978 to 1993. The linear econometric model considers a countryspecific error component, employs fixed-effects and random-effects estimation, and instruments for potentially endogenous explanatory variables with a fixed-effects system. The results, based on several different measures of flight, highlight the importance of modelling flight with a country-specific error component. While other proxies of the risk associated with macroeconomic imbalance are not significant, the central government surplus is negatively, statistically significant.

5. The concept of risk asymmetry underpins the theoretical work attempting to explain the simultaneity of capital inflows and outflows many developing nations experienced in the late 1970s and early 1980s. This work proposes that domestic investors face greater risk of loss than do foreign investors on their investment in a developing economy. Dooley (1988) performs country-specific fixed-effects IV estimation for five developing countries between 1976 and 1983. The model considers inflation, financial repression, and a risk premium on external debt as explanatory variables. Dooley instruments for inflation and financial repression using the fiscal deficit/GNP and debt/GNP, and interest payments/GNP, respectively. The nations in the sample included Argentina, Brazil, Mexico, the Philippines, and Venezuela.

6. Cuddington (1986) posits a demand equation for foreign assets based upon a stock-adjustment portfolio model where the assets include a domestic inflation hedge, and a domestic and foreign interest bearing asset. He estimates the model separately using yearly data from 1974 to 1982 for eight countries: Argentina, Brazil, Chile, Korea, Mexico, Peru, Uruguay, and Venezuela using OLS and IV estimation.

7. After controlling for capital outflows associated with trade and normal portfolio transactions, Varman (1989) regresses total capital outflows on dummy variables which assume values of one during those years in which she deems political and economic disarray to have prompted capital flight. She measures total capital out flows as the change in total external claims and calculates the total external claims according to Dooley's methodology of combining external debt statistics with capitalized balance of payments flows. She employs OLS and 2SLS to analyze flight from India from 1971 to 1985 and the Philippines from 1976 to 1985. Note that Varman \& Schneider (1989) tests whether the particular dummy event structure for flight imposed in Varman (1989) is consistent with the data. In doing so Varman \& Schneider (1989) employ flexible least squares. The structure imposed on India is confirmed, while that for the Philippines is not.

8. Jodice and Taylor (1983) constructed a political risk/instability index, but its coverage ended in 1982. Based on Bienen and van de Walle (1991), we constructed a variable that indicated when a change in executive leadership occurred. To incorporate when the change in executive leadership also entailed a switch in the governing party, we adjusted this variable after consulting various issues of Banks' Political Handbook of the World. These measures of political instability, however, do not capture instability unless it is associated with a change in leadership; this is not necessarily representative of political risk. If the political system entails a regularly timetable for elections, higher government turnover may not be a sound indicator of instability. Given this and the fact that these variables were very insignificant in all the estimations, we turned to other risk measures.

9. We note the difficulty associated with employing data on black market exchange rates. First, since black markets are often thin, the rate data may be noisy. Second, the black market premium does not just reflect the potential for official devaluation. The premium itself is affected by the costs associated with using the black market such as the risk of detection. Also, it reflects the decision by exporters as to how much to surrender to the black market, which is a function of the premium itself. 
10. The capital control measure employed in this paper likely fails to capture the overall effectiveness, or degree of tightness, of a capital control regime. Schineller (1997) considers different types of current and capital account controls, not merely restrictions on new capital account outflows. These include restrictions on payments for current and capital transactions, cost-related import restrictions, the need to surrender or repatriate export proceeds, and whether there are separate exchange rate(s) for some or all capital transactions and/or some or all invisibles.

11. For the random-effects specification, we continue to assume that $\mathrm{E}\left(\eta_{\mathrm{i}} \mid \mathrm{x}_{\mathrm{it}}\right)=0$, but $\mathrm{E}\left(v_{\mathrm{it}} \mid \mathrm{x}_{\mathrm{it}}\right) \neq 0$. In a linear random-effects model, should $\mathrm{E}\left(\eta_{\mathrm{i}} \mid \mathrm{x}_{\mathrm{it}}\right) \neq 0$, Hausman and Taylor (1981) provides the proper estimation technique to correct for this correlation. If we were to account for such a correlation in a nonlinear panel data model, we would appeal to Chamberlain (1980).

12. The reduced form modelling of the black market premium is premised on Dornbusch et. al. (1983), Fishelson (1988), Kaufman and O'Connell (1990), Agenor (1990), and Phylaktis (1992). In its most comprehensive form, the structural equation for the black market premium in our three equation system includes: the real official exchange rate, the differential in domestic and foreign interest rates adjusted for actual depreciation of the official exchange rate, domestic money supply (M1) growth, GNP growth, the presence of capital controls, and capital flight.

13. The reduced form modelling of the central government surplus is premised on Roubini and Sachs (1989). In its most general form, this structural equation includes the lagged domestic real deposit rate and U.S. Treasury Bill rate, lagged public external debt, consumer-price inflation and GNP growth, and capital flight.

14. The Newey, or AGLS-MCS, consistent and asymptotically efficient estimates of $\beta$, and $\sigma$ or $\sigma_{\eta}$ and $\sigma_{v}$ are based on several underlying regressions which are summarized briefly here and detailed in Appendix 2. First, using OLS we estimate the linear, reduced-form equations for the endogenous explanatory variables, the black market premium and government surplus. We then apply MLE to two, different nonlinear (two-threshold Tobit) regressions of capital flight. The first nonlinear estimation entails regressing capital flight on its reduced-form determinants and the residuals from the black market premium and government surplus OLS estimations. To form the appropriate AGLS transformation matrix required to recover a consistent and efficient $\beta$ necessitates two auxiliary estimations--both a second nonlinear and OLS estimation. The second nonlinear regression corresponds to the Two Stage Instrumental Variable (2SIV) estimation proposed by Blundell and Smith (1986) which yields consistent, but inefficient parameter estimates for the nonlinear model. In this 2SIV estimation, we regress flight on its structuralform determinants and both the fitted values and residuals from the black market premium and government surplus linear (OLS) reduced-form estimations. Then we perform reduced-form, OLS estimations of appropriately-transformed black market premium and government surplus variables. Output from these two auxiliary regressions underpin the AGLS transformation matrix used to recover the nonlinear, structural $\beta$ coefficient from the initial nonlinear reduced-form estimation of capital flight. We now use this result to construct the appropriate, modified-MCS transformation matrices needed the recover an efficient estimate of $\sigma$ or $\sigma_{\eta}$ and $\sigma_{v}$.

15. We also estimated the model with censored flight that corresponds with the 10th, 40th and 50th percentiles. The results were in line with those from the 20th, 25th and 30th percentiles that we report in this paper.

16. Argentina suffered from significant flight from the late 1970s through 1982; however, since its capital account was relatively open, the black market premium was close to zero. Similarly, in the late 1980s, the Philippines experienced flight as the Marcos regime was in turmoil. However, since the peso 
was floating, there was not a large black market premium. The World Bank Development Report (1989) notes that Mexico and Venezuela permitted freer capital movements than Sweden when they experienced flight; rising political risk in Venezuela prompted massive flight, but the black market premium was negligible in light of the open capital account. Similarly, Malaysia suffered large flight, but had almost no black market premium as the rupiah floated and the capital account was open. Meanwhile Brazil restricted capital flows and did not experience nearly as much flight as its Latin American neighbors initially and it did exhibit a relatively large premium.

17. We did not instrument for the expected adjusted, interest-rate differential due to the number of feasibly admissible regressors in the reduced-form, auxiliary nonlinear regressions. 


\section{Appendix 1: Econometric Methods for Limited Dependent Variables Models for Panel Data}

The cross-section time-series limited dependent variable model is

where actual $\mathrm{y}_{\mathrm{it}}$ is a function of "desired" $\mathrm{y}_{\mathrm{it}}{ }^{*}$ according to

$$
\begin{array}{ll}
y_{i t}{ }^{*}=x_{i t}{ }^{\prime} \beta+\varepsilon_{i t}, & i=1, \ldots, N, \\
& t=1, \ldots, T,
\end{array}
$$

$$
\mathrm{y}_{\mathrm{it}}=\tau\left(\mathrm{y}_{\mathrm{it}}{ }^{*}\right) \text {. }
$$

The function $\tau(\cdot)$ specifies the nonlinear rule that relates the unobserved latent variable $\mathrm{y}_{\mathrm{it}}{ }^{*}$ to the observed $\mathrm{y}_{\mathrm{it}} \cdot$ With a Tobit specification, $\tau(\cdot)$ satisfies:

$\begin{array}{lll}(1.3) \tau(\cdot): & y_{\mathrm{it}}=\mathrm{y}_{\mathrm{it}}{ }^{*} & \text { if } \mathrm{y}_{\mathrm{it}}{ }^{*}<\mathrm{c}^{\mathrm{l}}, \\ & \mathrm{y}_{\mathrm{it}}=0 & \text { if } \mathrm{c}^{\mathrm{l}} \leq \mathrm{y}_{\mathrm{it}}{ }^{*} \leq \mathrm{c}^{\mathrm{h}}, \\ & \mathrm{y}_{\mathrm{it}}=\mathrm{y}_{\mathrm{it}}{ }^{*} & \text { if } \mathrm{y}_{\mathrm{it}}{ }^{*} \mathrm{c}^{\mathrm{h}} .\end{array}$

For a serially uncorrelated, homoscedastic error term,

$$
\varepsilon_{\mathrm{it}} \sim \operatorname{iid} \mathrm{N}\left(0, \sigma^{2}\right)
$$

the log-likelihood function is

$$
\begin{aligned}
& \mathrm{L}\left(\beta, \Sigma_{\varepsilon}\right)=\ln \left[\sum_{\mathrm{y}_{\mathrm{it}}=\mathrm{y}_{\mathrm{it}}{ }^{*}}^{\mathrm{N}} 1 / \sigma \phi\left(\left(\mathrm{y}_{\mathrm{it}}-\mathrm{x}_{\mathrm{it}}{ }^{\mathrm{T}} \beta\right) / \sigma\right)+\right. \\
& \left.\sum_{\mathrm{y}_{\mathrm{it}}=0}^{\mathrm{N}} \sum^{\mathrm{T}}\left[\Phi\left(\left(\mathrm{c}^{\mathrm{h}}-\mathrm{x}_{\mathrm{it}}^{\mathrm{i}} \beta\right) / \sigma\right)-\Phi\left(\left(\mathrm{c}^{1}-\mathrm{x}_{\mathrm{it}}^{\mathrm{j}} \beta\right) / \sigma\right)\right]\right],
\end{aligned}
$$

where $\Sigma_{\varepsilon}=\sigma^{2} \mathrm{I}_{\mathrm{NT}}$, such that $\mathrm{I}_{\mathrm{NT}}$ is an NTxNT identity matrix, and $\phi(\cdot)$ and $\Phi(\cdot)$ are the density function and the distribution function of a standard, normal random variable, respectively. Assuming that $\mathrm{E}\left(\varepsilon_{\mathrm{it}} \mid \mathrm{x}_{\mathrm{it}}\right)=0$, MLE of this log-likelihood function yields consistent and asymptotically efficient parameter estimates of $\beta$ and $\sigma$.

When using panel data, it is usually more appropriate to control for possible country-specific heterogeneity. Modelling unobserved persistent country-specific heterogeneity with a one-factor randomerror components model:

$$
\varepsilon_{\mathrm{it}}=\eta_{\mathrm{i}}+\mathrm{v}_{\mathrm{it}},
$$

where

and

$$
\eta_{\mathrm{i}} \sim \operatorname{iid} \mathrm{N}\left(0, \sigma_{\eta}^{2}\right),
$$

$$
v_{\text {it }} \sim \text { iid } \mathrm{N}\left(0, \sigma_{v}^{2}\right)
$$

yields a variance-covariance matrix $\Sigma_{\varepsilon}$ of the form

$$
\Sigma_{\varepsilon}=\sigma^{2}{ }_{v} \mathrm{I}_{\mathrm{NT}}+\sigma_{\eta}^{2}\left(\mathrm{I}_{\mathrm{NT}} \otimes \mathrm{i}_{\mathrm{T}} \mathrm{i}_{\mathrm{T}}{ }^{\prime}\right)
$$

where $\mathrm{i}_{\mathrm{T}}$ is a Tx1 unit vector and $\otimes$ the Kronecker product. In the log-likelihood function for this onefactor random error components model, each country $i$ 's probability density function is conditional on $\eta_{\mathrm{i}}$ to control for unobserved, persistent heterogeneity. The conditional log-likelihood function is of the general form

$$
\left.L\left(\beta, \Sigma_{\varepsilon}\right)=\sum^{N} \ln \left\{\int \propto \prod_{-\infty} f\left(y_{i t} \mid \eta_{i}\right)\right] g\left(\eta_{i}\right) d \eta_{i}\right\},
$$

where $f\left(y_{i t} \mid \eta_{i}\right)$ is the density of $y_{i t}$ conditional on $\eta_{i}$. 
For the two-threshold Tobit specification, (1.8) becomes

(1.9)

$$
\begin{aligned}
& \mathrm{L}\left(\beta, \Sigma_{\varepsilon}\right)=\sum^{\mathrm{N}} \ln \left\{\int _ { - \infty } ^ { \infty } \left[\prod_{\mathrm{y}_{\mathrm{it}}=\mathrm{y}_{\mathrm{it}}{ }^{\mathrm{T}}}^{\mathrm{T}} 1 / \sigma_{\mathrm{v}} \phi\left(\left(\mathrm{y}_{\mathrm{it}}-\mathrm{x}_{\mathrm{it}}{ }^{\prime} \beta-\eta_{\mathrm{i}}\right) / \sigma_{\mathrm{v}}\right)\right.\right. \\
& \left.\left.* \prod_{\mathrm{y}_{\mathrm{it}}=0}^{\mathrm{T}}\left[\Phi\left(\left(\mathrm{c}^{\mathrm{h}}-\mathrm{x}_{\mathrm{it}}{ }^{\prime} \beta-\eta_{\mathrm{i}}\right) / \sigma_{\mathrm{v}}\right)-\Phi\left(\left(\mathrm{c}^{1}-\mathrm{x}_{\mathrm{it}}{ }^{\prime} \beta-\eta_{\mathrm{i}}\right) / \sigma_{v}\right)\right]\right] \mathrm{g}\left(\eta_{\mathrm{i}}\right) \mathrm{d} \eta_{\mathrm{i}}\right\},
\end{aligned}
$$

where once again $\phi(\cdot)$ and $\Phi(\cdot)$ are, respectively, the density function and the distribution function of a standard, normal random variable. In addition, we assume that $g\left(\eta_{\mathrm{i}}\right)$ is $1 / \sigma_{\eta} \phi\left(\eta_{\mathrm{i}} / \sigma_{\eta}\right)$, the density function for a standard, normal random variable. We utilize Gaussian quadrature to integrate over the $\eta_{\mathrm{i}} \mathrm{s}$. Once done, the remaining randomness stems from the $v_{\mathrm{it}} \mathrm{s}$. Consequently maximization of (1.9) yields consistent and asymptotically efficient estimates of $\beta$ and $\Sigma_{\varepsilon}$, assuming $\mathrm{E}\left(\eta_{\mathrm{i}} \mid \mathrm{x}_{\mathrm{it}}\right)=0$ and $\mathrm{E}\left(\mathrm{v}_{\mathrm{it}} \mid \mathrm{x}_{\mathrm{it}}\right)=0$. 


\section{Appendix 2: Implementation of Newey (1987)}

We posit that a subset of the explanatory variables in this censored regression model exhibits simultaneity with the limited dependent variable. Newey (1987) outlines the estimation methodology that yields asymptotically efficient and consistent parameter estimates for such a limited dependent variable model with linearly-determinined endogenous explanatory variables. The model notation for capital flight introduced in equation (1) is:

$$
\begin{aligned}
& \mathrm{y}_{\mathrm{it}}{ }^{*}=\mathrm{x}_{\mathrm{it}}{ }^{\mathrm{j}} \beta+\varepsilon_{\mathrm{it}}, \quad \mathrm{i}=1, \ldots, \mathrm{N} \\
& \mathrm{t}=1, \ldots, \mathrm{T} \text {. }
\end{aligned}
$$

In this appendix, we modify the expression for the latent variable $\mathrm{y}_{\mathrm{it}}{ }^{*}$ in $(2.1)$ in order to differentiate between the endogenous and exogenous explanatory variables, $\mathrm{x}_{\mathrm{it}}$. In doing so, we employ the notation used by Newey (1987). Re-writing the structural expression for $\mathrm{y}_{\mathrm{it}}{ }^{*}$,

$$
\mathrm{y}^{*}{ }_{\mathrm{it}}=\mathrm{Y}_{\mathrm{it}} \beta_{0}+\mathrm{X}_{1 \mathrm{it}} \gamma_{0}+\varepsilon_{\mathrm{it}}=\mathrm{Z}_{\mathrm{it}} \delta_{0}+\varepsilon_{\mathrm{it}}, \quad \begin{aligned}
& \mathrm{i}=1, \ldots, \mathrm{N} \\
& \mathrm{t}=1, \ldots, \mathrm{T} .
\end{aligned}
$$

$\mathrm{Z}_{\mathrm{it}}=\left[\mathrm{Y}_{\mathrm{it}}, \mathrm{X}_{\mathrm{it}}\right]$ and $\delta_{0}=\left(\beta_{0}{ }^{\prime}, \gamma_{0}{ }^{\prime}\right)^{\prime}$, where $\mathrm{Y}_{\mathrm{it}}$ is the $i t^{\text {th }}$ observation of a $1 \mathrm{xr}$ vector of endogenous explanatory variables, $\mathrm{X}_{1 \mathrm{it}}$ is a $1 \mathrm{xs}$ vector of (included) exogenous explanatory variables, and $\delta_{0}$ is the qx1 vector of regression parameters for this equation with $\mathrm{q} \equiv \mathrm{r}+\mathrm{s}$.

In our model of flight,

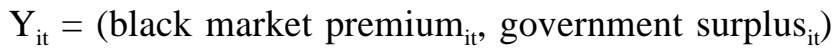

and

$$
\mathrm{X}_{1 \mathrm{it}}=\left(\text { constant }_{\mathrm{it}} \text {, interest rate differential } \mathrm{i}_{\mathrm{i}}, \mathrm{IMF} \text { program }_{\mathrm{it}} \text {, capital controls } \mathrm{s}_{\mathrm{it}}\right) \text {. }
$$

The endogenous explanatory variables $\mathrm{Y}_{\mathrm{it}}$ will be assumed to be related to a $1 \mathrm{xK}$ vector of instrumental variables $\mathrm{X}_{\mathrm{it}}$. Denote the reduced form for $\mathrm{Y}_{\mathrm{it}}$ as:

$$
\begin{aligned}
Y_{\mathrm{it}}= & \mathrm{X}_{\mathrm{it}} \Pi_{0}+\mathrm{V}_{\mathrm{it}} \\
& =\mathrm{X}_{1 \mathrm{it}} \Pi_{10}+\mathrm{X}_{2 \mathrm{it}} \Pi_{20}+\mathrm{V}_{\mathrm{it}} .
\end{aligned}
$$

$\mathrm{X}_{2 \mathrm{it}}$ is a $1 \mathrm{x}(\mathrm{K}-\mathrm{s})$ vector of (excluded) exogenous variables; thus, $\mathrm{X}_{\mathrm{it}}=\left[\mathrm{X}_{1 \mathrm{it}}, \mathrm{X}_{2 \mathrm{it}}\right]$ and $\Pi_{0}=\left[\Pi_{10}, \Pi_{20}{ }^{\prime}\right]^{\prime}$, which is a Kxr matrix of coefficients. $\mathrm{V}_{\text {it }}$ is a $1 \mathrm{xr}$ vector of disturbances. In this model,

$$
\begin{gathered}
\mathrm{X}_{2 \mathrm{it}}=\left(\text { consumer-price inflation }_{\mathrm{it}} \text {, lagged U.S. Treasury Bill rate }_{\mathrm{it}}\right. \text {, } \\
\text { lagged public external } \left.\text { debt }_{\mathrm{it}} \text {, GNP growth }{ }_{\mathrm{it}}\right) .
\end{gathered}
$$

After substituting (2.4) into (2.2), the reduced-form two-threshold Tobit model for capital flight is

$$
\begin{aligned}
\mathrm{y}^{*}{ }_{\mathrm{it}}= & \left(\mathrm{X}_{\mathrm{it}} \Pi_{0}+\mathrm{V}_{\mathrm{it}}\right) \beta_{0}+\mathrm{X}_{1 \mathrm{it}} \gamma_{0}+\varepsilon_{\mathrm{it}} \\
= & \mathrm{X}_{\mathrm{it}} \alpha_{0}+v_{\mathrm{it}},
\end{aligned}
$$

where $v_{\text {it }}=\varepsilon_{\text {it }}+V_{\text {it }} \beta_{0} \cdot \alpha_{0}=D_{0} \delta_{0}$, where $D_{0} \equiv\left[\Pi_{0}, I_{1}\right]$ and $I_{1}$ is a Kxs selection matrix such that $X_{1 \mathrm{it}}=$ $\mathrm{X}_{\mathrm{it}} \mathrm{I}_{1}$. 
Following Newey (1987), we assume that

$$
\left(\varepsilon_{\mathrm{it}}, \mathrm{v}_{\mathrm{it}}\right) \sim \mathrm{N}(0, \Sigma)
$$

which can be satisfied by both $\varepsilon_{\mathrm{it}} \sim$ iid $\mathrm{N}\left(0, \sigma_{\varepsilon}^{2}\right)$ and by $\varepsilon_{\mathrm{it}}=\eta_{\mathrm{i}}+v_{\mathrm{it}}$, where $\eta_{\mathrm{i}} \sim$ iid $\mathrm{N}\left(0, \sigma_{\eta}^{2}\right)$ and $v_{\mathrm{it}} \sim$ iid $\mathrm{N}\left(0, \sigma_{v}^{2}\right)$. This assumption of multivariate normality permits us to obtain a likelihood function for $\mathrm{y}^{*}{ }_{\mathrm{it}}$ conditional on $\mathrm{Y}_{\mathrm{it}}$. Conditional on $\mathrm{Y}_{\mathrm{it}}$,

where

$$
\varepsilon_{\mathrm{it}} \sim \mathrm{N}\left(\mathrm{V}_{\mathrm{it}} \rho, \sigma^{2}\right),
$$

and

$$
\rho=\Sigma_{22}^{-1} \Sigma_{21}
$$

$$
\sigma^{2}=\Sigma_{11}-\Sigma_{12} \Sigma_{22}^{-1} \Sigma_{21}
$$

such that $\Sigma$ is partitioned conformably with $\varepsilon_{\mathrm{it}}$ and $\mathrm{V}_{\mathrm{it}}$. When $\varepsilon_{\mathrm{it}} \sim$ iid $\mathrm{N}\left(0, \sigma_{\varepsilon}^{2}\right)$,

$$
\Sigma_{11}=\sigma_{\varepsilon}^{2} I_{\mathrm{NT}}
$$

and $\mathrm{I}_{\mathrm{NT}}$ is an NTxNT identity matrix. However, when $\varepsilon_{\mathrm{it}}=\eta_{\mathrm{i}}+v_{\mathrm{it}}$,

$$
\Sigma_{11}=\sigma_{v}^{2} \mathrm{I}_{\mathrm{NT}}+\sigma_{\eta}^{2}\left(\mathrm{I}_{\mathrm{NT}} \otimes \mathrm{i}_{\mathrm{T}} \mathrm{i}_{\mathrm{T}}{ }^{\prime}\right),
$$

and $\mathrm{i}_{\mathrm{T}}$ is a Tx1 unit vector and $\otimes$ denotes the Kronecker product. It follows that conditional on $\mathrm{Y}_{\mathrm{it}}$,

$$
\mathrm{y}^{*}{ }_{\mathrm{it}} \sim \mathrm{N}\left(\mathrm{Z}_{\mathrm{it}} \delta_{0}+\mathrm{V}_{\mathrm{it}} \rho, \sigma^{2}\right)
$$

Thus, the reduced-form likelihood function for $\mathrm{y}_{\mathrm{it}}{ }^{*}$ conditional on $\mathrm{Y}_{\mathrm{it}}$ for each $i t^{\text {th }}$ observation has the form

$$
\mathrm{l}_{\mathrm{it}}(\delta, \Pi, \Sigma, \psi)=1\left(\mathrm{y}_{\mathrm{it}}, \mathrm{Z}_{\mathrm{it}} \delta+\left(\mathrm{Y}_{\mathrm{it}}-\mathrm{X}_{\mathrm{it}} \Pi\right) \rho, \sigma^{2}, \psi\right)
$$

where $\psi$ stems from $\mathrm{y}_{\mathrm{it}}=\tau\left(\mathrm{y}_{\mathrm{it}}{ }^{*}, \psi\right)$; for our Tobit model $\psi=0$. In the two-threshold Tobit model,

$$
\left.1_{\mathrm{it}}(\delta, \Pi, \Sigma, \psi)=1 / \sigma_{v} \phi\left(\mathrm{y}_{\mathrm{it}}-\mathrm{Z}_{\mathrm{it}} \delta-\left(\mathrm{Y}_{\mathrm{it}}-\mathrm{X}_{\mathrm{it}} \Pi\right) \rho-\eta_{\mathrm{i}}\right) / \sigma_{v}\right)
$$

when $\mathrm{y}_{\mathrm{it}} \neq 0$, and

$$
\begin{aligned}
& 1_{\mathrm{it}}(\delta, \Pi, \Sigma, \psi)= \\
& \begin{array}{l}
\Phi\left(\left(\mathrm{c}^{\mathrm{h}}-\mathrm{Z}_{\mathrm{it}} \delta-\left(\mathrm{Y}_{\mathrm{it}}-\mathrm{X}_{\mathrm{it}} \Pi\right) \rho-\eta_{\mathrm{i}}\right) / \sigma_{\mathrm{v}}\right)- \\
\Phi\left(\left(\mathrm{c}^{1}-\mathrm{Z}_{\mathrm{it}} \delta-\left(\mathrm{Y}_{\mathrm{it}}-\mathrm{X}_{\mathrm{it}} \Pi\right) \rho-\eta_{\mathrm{i}}\right) / \sigma_{\mathrm{v}}\right)
\end{array}
\end{aligned}
$$

when $\mathrm{y}_{\mathrm{it}}=0 . \phi(\cdot)$ and $\Phi(\cdot)$ are, respectively, the density function and the distribution function of a standard, normal random variable. Note that when $\varepsilon_{\mathrm{it}} \sim$ iid $\mathrm{N}\left(0, \sigma_{\varepsilon}^{2}\right)$, the $\eta_{\mathrm{i}}$ term vanishes and $\sigma_{v}$ becomes $\sigma_{\varepsilon}$.

Newey proposes estimating the structural parameter $\delta_{0}$ in (2.2) by first estimating the reduced form parameters in the system and then applying AGLS to the estimate of $\alpha_{0}=\mathrm{D}_{0} \delta_{0}$ in (2.6). This procedure entails including the residuals from the linear reduced-form estimations of the endogenous explanatory variables as additional explanatory variables in the reduced-form two-threshold Tobit estimation. Define 


$$
\theta=\left(\theta_{1}, \theta_{2}^{\prime}\right)^{\prime}
$$

such that

$$
\theta_{1}=\operatorname{vec}(\Pi)
$$

and

Then,

$$
\theta_{2}=\left(\alpha^{\prime}, \lambda, \sigma^{2}\right)^{\prime}=\left(\alpha^{\prime}, \eta^{\prime}\right)^{\prime}
$$

$\theta_{1}$ is estimated using OLS: $\hat{\theta}_{1}$, and $\theta_{2}$ is the MLE two-step estimator satisfying

$$
\begin{array}{lll}
\max & \mathrm{L}= & \ln \sum \sum \mathrm{1}_{\mathrm{it}}\left(\hat{\theta}_{1}, \theta_{2}\right), \\
& \theta_{2} & \mathrm{NT}
\end{array}
$$

or

$$
\begin{aligned}
& \max \quad \mathrm{L}=\ln \sum \sum 1\left(\mathrm{y}_{\mathrm{it}}, \mathrm{X}_{\mathrm{it}} \alpha+\hat{\mathrm{V}}_{\mathrm{it}} \lambda, \sigma^{2}, \psi\right) \text {, } \\
& \left(\alpha, \lambda, \theta_{2}, \psi\right) \quad \mathrm{N} \mathrm{T}
\end{aligned}
$$

where $\hat{V}_{i t}$ is an element of the vector of OLS residuals. Should $\varepsilon_{i t}=\eta_{i}+v_{i t}$, the estimate of $\theta_{2}$ is gotten by performing MLE on:

$$
\left.L=\sum_{i=1}^{N} \ln \left\{\int_{-\infty}^{\infty}\left[\prod_{t=1}^{T} 1_{i t}\left(\hat{\theta}_{1}, \theta_{2}\right) \mid \eta_{i}\right)\right] g\left(\eta_{i}\right) d \eta_{i}\right\} .
$$

Applying AGLS to the appropriate elements of $\hat{\theta}_{2}$ yields asymptotically consistent and efficient estimates of $\delta_{0}{ }^{\prime}=\left(\beta_{0}{ }^{\prime}, \gamma_{0}{ }^{\prime}\right)$.

Put differently, this estimation procedure entails the following. First estimate $\Pi_{0}$ by performing OLS on the reduced-form model of $\mathrm{Y}_{\mathrm{it}}$. This estimation yields $\hat{\prod}_{\mathrm{f}}$, a Kxr matrix of parameter estimates. Let $\hat{V}_{i t}$ denote the $1 \mathrm{xr}$ residuals from this regression and $\hat{\mathrm{Y}}_{\mathrm{it}}=\mathrm{X}_{\mathrm{it}} \hat{\Pi}_{\mathrm{f}}$ the $1 \mathrm{xr}$ vector of fitted values from this regression. Next consider the reduced form

$$
\begin{aligned}
\mathrm{y}^{*}{ }_{\mathrm{it}}= & \mathrm{X}_{\mathrm{it}} \alpha+\left(\mathrm{Y}_{\mathrm{it}}-\mathrm{X}_{\mathrm{it}} \Pi_{0}\right) \lambda \\
& =\mathrm{X}_{\mathrm{it}} \alpha+\mathrm{V}_{\mathrm{it}} \lambda,
\end{aligned}
$$

where $\alpha$ is a $\operatorname{Kx} 1$ vector of coefficients and $\eta \equiv(\lambda, \sigma)^{\prime}$ is the $(r+1) x 1$ vector of nuisance parameters. Substitute the residuals $\hat{V}^{\text {ti }}$ into this expression and perform MLE on

$$
\mathrm{L}\left(\mathrm{y}_{\mathrm{it}}, \mathrm{X}_{\mathrm{it}} \alpha+\hat{\mathrm{V}}_{\mathrm{it}} \lambda, \sigma^{2}, \psi\right) \text {. }
$$

MLE of ${ }_{\hat{\alpha}}(2.15)$ yields $\hat{\alpha} \hat{\eta} \equiv(\hat{\lambda}, \hat{\sigma})^{\prime}$ and the variance covariance matrix $\hat{(J)}^{-1}$. To recover an estimate of $\delta_{0}$ from $\alpha$, we employ AGLS.

In order to construct the appropriate AGLS transformation matrix $\hat{\Omega}$, we must perform two auxiliary estimations. First, we must obtain a consistent estimate of $\beta_{0}$. Such an estimate stems from performing MLE on the likelihood function associated with the reduced form

$$
\begin{array}{r}
\mathrm{y}^{*}{ }_{\mathrm{it}}=\hat{\mathrm{Y}}_{\mathrm{it}} \beta+\mathrm{X}_{\text {lit }} \gamma+\left(\hat{\mathrm{Y}}_{\mathrm{it}}-\mathrm{X}_{\mathrm{it}} \hat{\Lambda}_{\hat{f}}\right) \lambda \\
=\left(\mathrm{X}_{\mathrm{it}} \prod_{\mathrm{f}}\right) \beta+\mathrm{X}_{\mathrm{lit}} \gamma+\mathrm{V}_{\mathrm{it}} \lambda .
\end{array}
$$

The resulting $\hat{\beta}$ is the 2 SIV estimator proposed by Smith and Blundell (1986), which is consistent, but not efficient. Using this $\hat{\beta}$ and the $\hat{\lambda}$ obtained from MLE of (2.15) we regress $Y_{i t}(\hat{\lambda}-\hat{\beta})$ on $X_{i t}$ using OLS. 


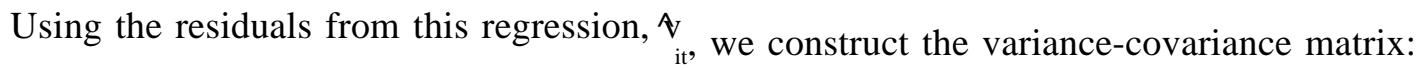

$$
\begin{aligned}
& \sum^{\wedge}{ }^{2}{ }^{2}\left(X^{\prime} \mathrm{X}\right)^{-1} /(\mathrm{NT}-\mathrm{K}) . \\
& \text { NT }
\end{aligned}
$$

Combining this variance-covariance matrix with the first $\alpha$ rows and columns of $\hat{J}^{1}$ yields the KxK AGLS transformation matrix $\Omega$

$$
\left.\hat{\Omega}=\hat{\mathbf{J}}^{1}\right)_{\alpha \alpha}+\sum_{\mathrm{NT}}^{\hat{\mathrm{V}}_{\mathrm{it}}^{2}} *\left(\mathrm{X}^{\prime} \mathrm{X}\right)^{-1} /(\mathrm{NT}-\mathrm{K}) .
$$

The $(\mathrm{r}+\mathrm{s}) \mathrm{x} 1$ AGLS estimate of $\delta_{0}$ is

$$
\delta_{\mathrm{AGLS}}=\left(\hat{\mathrm{D}}^{\prime} \hat{\Omega}^{-1} \hat{\mathrm{D}}\right)^{-1} \hat{\mathrm{D}}^{\wedge} \hat{\Omega}^{1} \hat{\alpha}
$$

where $\hat{\mathrm{D}} \equiv\left[\hat{\bigcap} \mathrm{I}_{1}\right]$ and $\mathrm{I}_{1}$ is a Kxs selection matrix such that $\mathrm{X}_{1 \mathrm{it}}=\mathrm{X}_{\mathrm{it}} \mathrm{I}_{1}$; thus, $\hat{\mathrm{D}}$ is $\mathrm{Kx}(\mathrm{r}+\mathrm{s})$. Recalling that $\delta_{\mathrm{AGLS}}{ }^{\prime}=\left(\beta_{\mathrm{AGLS}}, \gamma_{\mathrm{AGLS} S}\right)_{\lambda}$ we have recovered the structural parameters for equation of interest, the capital flight equation. $\left(D^{\prime} \Omega^{-1} D\right)^{-1}$ is the consistent asymptotic variance covariance matrix for these estimates.

While AGLS yields asymptotically consistent and efficient estimates of $\delta_{0}{ }^{\prime}=\left(\beta_{0}, \gamma_{0}{ }^{\prime}\right)$, it does not provide consistent and asymptotically efficient estimates of $\eta \equiv\left(\lambda^{\prime}, \sigma\right)^{\prime}$. Applying a MCS estimator to this limited information simultaneous information system would have yielded consistent and asymptotically efficient estimates of $\eta \equiv(\lambda, \sigma)^{\prime}$ as well as $\delta_{0}$. Since the MCS and AGLS estimates of $\delta_{0}$ are asymptotically equivalent, we can use $\delta_{\text {AGLS }}$ to concentrate $\eta$ out of the MCS estimator. In combining the AGLS and MCS estimation methodologies, we obtain estimates of $\eta$, as well as $\Pi$, which are asymptotically equivalent to those associated with the MCS estimator. Such a modified-MCS estimator is

$$
\left(\operatorname{vec}(\hat{\Pi})^{\prime}, \hat{\eta}^{\prime}\right)^{\prime}=\left(\hat{\mathrm{H}}_{\mathrm{A}}{ }^{\prime} \hat{\mathrm{C}}^{1} \hat{\mathrm{H}}_{\mathrm{A}}\right)^{-1} \hat{\mathrm{H}}_{\mathrm{A}}{ }^{\prime} \hat{\mathrm{C}}^{1} \tilde{\theta}
$$

To construct this estimator, we define

$$
\begin{aligned}
& \hat{\mathrm{H}}_{\mathrm{A}}=\left[\hat{\mathrm{H}}_{\mathrm{A} \Pi}, \hat{\mathrm{H}}_{\mathrm{A \eta}}\right], \\
& \hat{\mathrm{H}}_{\mathrm{A} \Pi}=\left[\mathrm{I}_{\mathrm{rK}}, \beta \otimes \mathrm{I}_{\mathrm{K}}, 0\right],
\end{aligned}
$$

where 0 is a null matrix of dimension $\mathrm{rKxm}, \mathrm{I}_{\mathrm{K}}$ is a $\mathrm{KxK}$ identity matrix and

$$
\hat{\mathrm{H}}_{\mathrm{A \eta}}{ }^{\prime}=\left(\partial \hat{\mathrm{h}} / \partial \hat{\eta}^{\prime}\right)^{\prime}
$$

where $\hat{h}=\left[\operatorname{vec}(\hat{\Pi})^{\prime},\left(\hat{D} \delta_{\text {AGLS }}\right)^{\prime}, \hat{\eta}\right]^{\prime}$. $m$ denotes the number of nuisance parameters in the estimation; $m=3$ in our model. Then, the dimension of $\hat{\mathrm{H}}_{\mathrm{A}}$ is $((1+\mathrm{r}) \mathrm{K}+\mathrm{m}) \mathrm{x}(\mathrm{rK}+\mathrm{m})$, the dimension of $\hat{\mathrm{H}}_{\mathrm{A} \Pi}$ is $((\mathrm{r}+1) \mathrm{K}$ $+\mathrm{m}) \mathrm{xrK}$ and that of $\hat{\mathrm{H}}_{\mathrm{A \eta}}$ ' is $((\mathrm{r}+1) \mathrm{K}+\mathrm{m}) \mathrm{xm}$. In addition, define

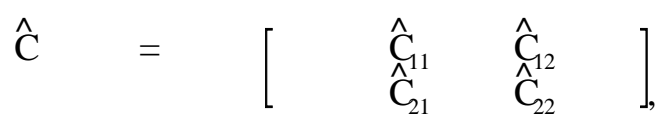

where

$$
\begin{aligned}
& \hat{\mathrm{C}}_{11}=\hat{\Sigma}_{22} \otimes \mathrm{Q}^{-1}, \\
& \hat{\mathrm{C}}_{21}=\hat{\lambda} \hat{\Sigma}_{22} \otimes \mathrm{SQ}^{-1},
\end{aligned}
$$


and

$$
\hat{\mathrm{C}}_{22}=\hat{\mathbf{J}}^{1}+\hat{\lambda} \hat{\Sigma_{22}} \hat{\lambda} \mathrm{SQ}^{-1} \mathrm{~S}^{\prime}
$$

In constructing $\hat{\mathrm{C}}$,

$$
\mathrm{S}=\left[\mathrm{I}_{\mathrm{K}}, 0\right]
$$

such that 0 is a null matrix of dimension $\mathrm{Kx}(\mathrm{r}+1)$,

and

$$
\mathrm{Q}=\mathrm{X}^{\prime} \mathrm{X}
$$

$$
\hat{\Sigma}_{22}=\hat{V}^{\hat{V}} /(\mathrm{NT}-\mathrm{K})
$$

After defining

$$
\hat{\theta}=\left(\operatorname{vec}(\hat{\Pi}), \hat{\alpha}, \hat{\eta}^{\prime}\right)^{\prime}
$$

we form $\tilde{\theta}$ such that $\tilde{\theta}=\hat{\theta}$, where we replace the elements corresponding to $\hat{\alpha}$ by

$$
\tilde{\alpha}=\hat{\alpha}-\mathrm{I}_{1} \gamma_{\mathrm{AGLS}}
$$

Thus, we obtain $\tilde{\theta}$, which is of dimension $((\mathrm{r}+1) \mathrm{K}+\mathrm{m}) \mathrm{x} 1$. Having done so, we can now form the modified-MCS estimator

$$
\left(\operatorname{vec}(\hat{\Pi}), \hat{\eta}^{\prime}\right)^{\prime}=\left(\hat{\mathrm{H}}_{\mathrm{A}}, \hat{\mathrm{C}}^{1} \hat{\mathrm{H}}_{\mathrm{A}}\right)^{-1} \hat{\mathrm{H}}_{\mathrm{A}}, \hat{\mathrm{C}}^{1} \tilde{\theta}
$$

This MCS-AGLS estimator yields an asymptotically consistent and efficient estimate of $\sigma$, the parameter we were interested in recovering, well as $\lambda$ and $\Pi$. We now have recovered all the structural parameters for the capital flight equation. 


\section{Appendix 3: Data Sources}

Abbreviation for Data Sources:

BOP: Balance of Payments Statistics, IMF, computer tape.

IFS: International Financial Statistics, IMF, computer tapes and various issues.

WDT: World Debt Tables, World Bank, computer tape.

WTA: World Tables, World Bank, computer diskette.

WCY: World Currency Yearbook, various issues.

IMF: IMF Staff Papers, Moshin S. Khan, "The Macroeconomic Effects of Fund-Supported Adjustment Programs", June 1990.

FX: Annual Report on Exchange Arrangements and Exchange Restrictions, IMF, various issues.

Variables:

Flight: WDT, BOP, and IFS.

GNP: IFS.

Official Exchange Rates (average): IFS.

Interest rates: IFS, national sources.

Black market exchange rates: WCY.

Consumer-price inflation: IFS.

Money supply (M1): IFS.

Central government surplus: IFS.

Public external debt: WDT.

IMF dummy variable: IMF.

Capital control dummy variable: FX. 


\section{Table 1 \\ CAPITAL FLIGHT \\ (Percent of GNP)}

\begin{tabular}{|c|c|c|c|}
\hline Year & Total & Aatin & $\frac{\text { Non-Latin }}{\text { America }}$ \\
\hline 1978 & 1.68 & 1.69 & 1.66 \\
\hline 1979 & 1.32 & 1.38 & 1.26 \\
\hline 1980 & 2.22 & 2.61 & 1.73 \\
\hline 1981 & 1.90 & 2.75 & 0.75 \\
\hline 1982 & 2.26 & 2.85 & 1.56 \\
\hline 1983 & 1.76 & 3.21 & 0.30 \\
\hline 1984 & 0.30 & 1.14 & -0.58 \\
\hline 1985 & 2.73 & 1.86 & 3.62 \\
\hline 1986 & 2.57 & 2.43 & 2.71 \\
\hline 1987 & 3.53 & 3.72 & 3.36 \\
\hline 1988 & -0.74 & -1.90 & 0.38 \\
\hline
\end{tabular}

Chart 1

CAPITAL FLIGHT

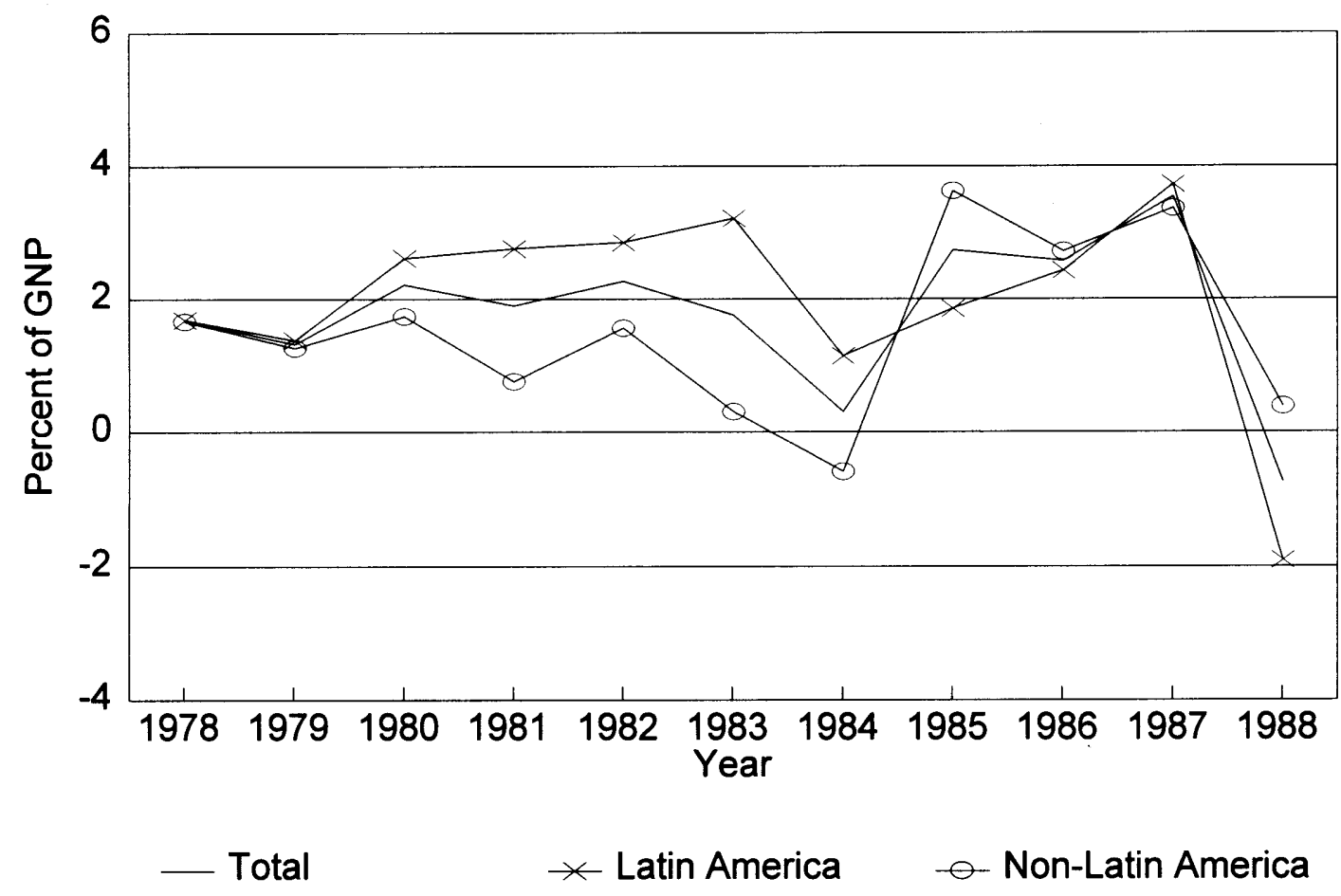



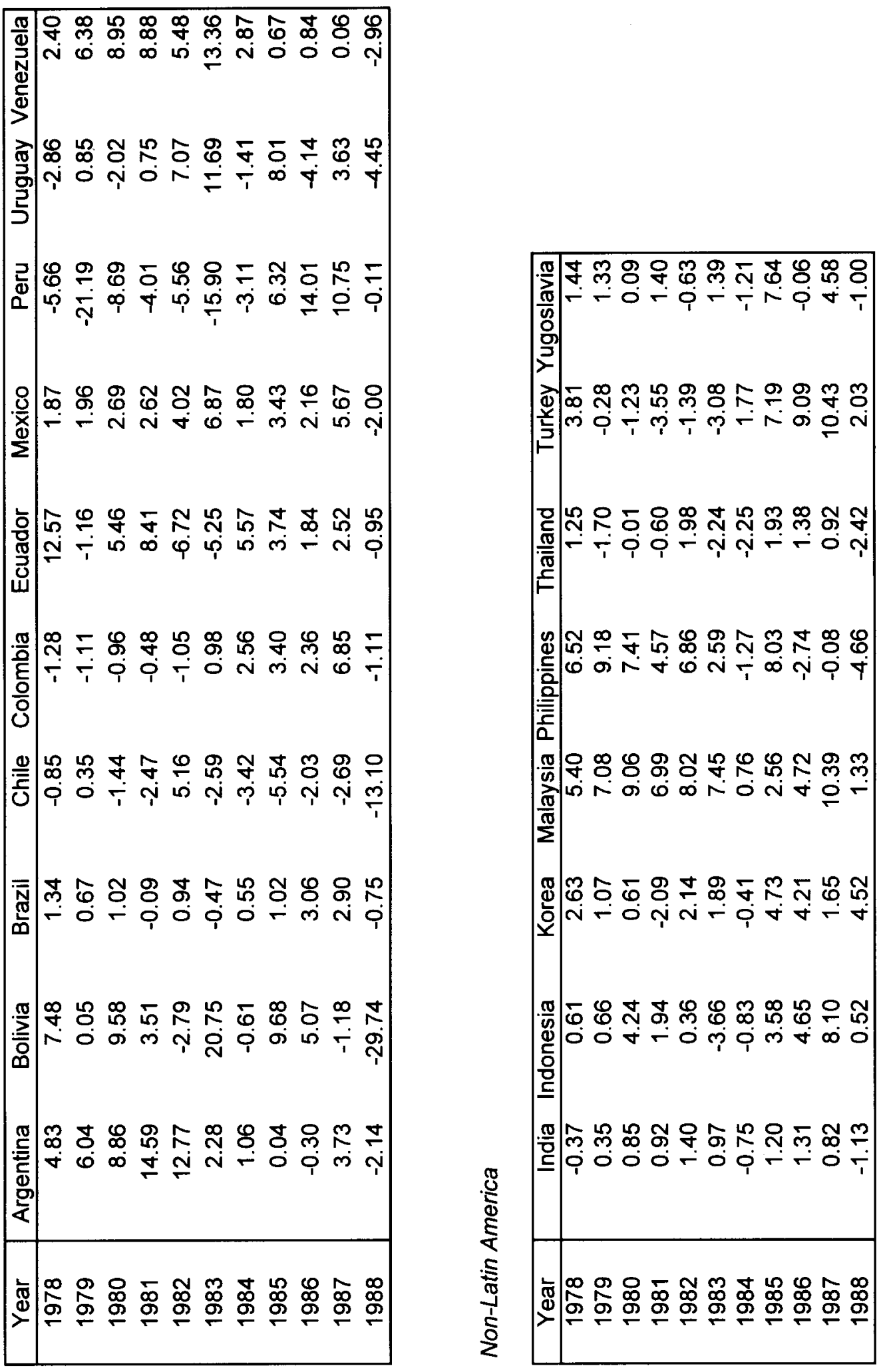
Table 3

\section{Nonlinear Estimation: Homogeneous Error Term}

Threshold values

20th Censored-Flight Percentile

(flight as percent of GDP)

Upper

Lower

Constant term

Interest rate differential

IMF program in effect

Capital controls

Black market premium

$\sigma$

Log-likelihood (2SIV)

Likelihood-Ratio test (Ho: $\beta=0$ )

Likelihood-Ratio test (Ho: joint exogeneity)

$\begin{array}{rrr}1.00 & 1.40 & 1.70 \\ -0.70 & -0.90 & -0.94\end{array}$

$\begin{array}{ccc}0.1048 & 0.1057 & 0.1059 \\ (0.0290) & (0.0291) & (0.0290) \\ ((3.6137))^{\mathrm{a}} & ((3.6385))^{\mathrm{a}} & ((3.6566))^{\mathrm{a}}\end{array}$

$\begin{array}{ccc}0.0001 & 0.0001 & 0.001 \\ (0.0000) & (0.0000) & (0.000) \\ ((1.4051)) & ((1.4815)) & ((1.4110))\end{array}$

$$
\begin{array}{lll}
-0.0102 & -0.0139 & -0.0138
\end{array}
$$$$
\begin{array}{lll}
(0.0065) & (0.0065) & (0.0065)
\end{array}
$$$$
((-2.1804))^{\mathrm{b}} \quad((-2.1253))^{\mathrm{b}} \quad((-2.1156))^{\mathrm{b}}
$$

$\begin{array}{ccc}0.0035 & 0.0037 & 0.0026 \\ (0.0078) & (0.0079) & (0.0078) \\ ((0.4452)) & ((0.4750)) & ((0.3327))\end{array}$

$\begin{array}{ccc}-0.0784 & -0.0795 & -0.0787 \\ (0.0281) & (0.0282) & (0.0281) \\ ((-2.7891))^{\mathrm{a}} & ((-2.8209))^{\mathrm{a}} & ((-2.8046))^{\mathrm{a}}\end{array}$

Central government surplus as share of GDP

$\begin{array}{ccc}-0.2078 & -0.2099 & -0.2101 \\ (0.1040) & (0.1041) & (0.1036) \\ ((-1.9977))^{\mathrm{b}} & ((-2.0157))^{\mathrm{b}} & ((-2.0267))^{\mathrm{b}} \\ & & \\ 0.03687 & 0.03692 & 0.0367 \\ (0.0504) & (0.0504) & (0.0504) \\ ((-65.5367))^{\mathrm{b}} & ((-65.4590))^{\mathrm{b}} & ((-65.5099))^{\mathrm{b}} \\ & & \\ 194.32 & 162.98 & 144.74\end{array}$

$21.10 \mathrm{a} \quad 20.50^{\mathrm{a}} \quad 21.24$

$6.77^{\mathrm{b}} \quad 6.66^{\mathrm{b}} \quad 6.55^{\mathrm{b}}$

(standard errors); ((t-statistics)); ${ }^{a}$ significant at the $1 \%$ level; ${ }^{b}$ significant at the $5 \%$ level. 
Table 4

Nonlinear Estimation: Heterogeneous Error Term

Threshold values

20th Censored-Flight Percentile

(flight as percent of GDP)

Upper

Lower

Constant term

Interest rate differential

IMF program in effect

Capital controls

Black market premium

Log-likelihood (2SIV)

Likelihood-Ratio test (Ho: $\beta=0)$

Likelihood-Ratio test (Ho: joint exogeneity)

Estimation conditional on: $\sigma_{\eta}=$

Central government surplus as share of GDP

$$
\begin{gathered}
-0.2232 \\
(0.1002) \\
((-2.2274))^{b}
\end{gathered}
$$

198.54

17.17

$-0.0823$

$(0.0291)$

$((0.9783))$

1.40

$-0.90$

1.70

$-0.94$

$\begin{array}{ccc}0.1037 & 0.1047 & 0.1039 \\ (0.0300) & (0.0301) & (0.0300) \\ ((3.4574))^{\mathrm{a}} & ((3.4811))^{\mathrm{a}} & ((3.4618))^{\mathrm{a}}\end{array}$

$\begin{array}{ccc}0.0001 & 0.0001 & 0.0001 \\ (0.0000) & (0.0000) & (0.000) \\ ((1.2921)) & ((1.3611)) & ((1.3020))\end{array}$

$\begin{array}{ccc}-0.0140 & -0.0136 & -0.0132 \\ (0.0065) & (0.0066) & (0.0065) \\ ((-2.1350))^{\mathrm{b}} & ((-2.0763))^{\mathrm{b}} & ((-2.0217))^{\mathrm{b}} \\ & & \\ 0.0094 & 0.0092 & .0076 \\ (0.0094) & (0.0094) & (0.0094) \\ ((1.0054)) & ((0.9783)) & ((0.8077))\end{array}$

$\begin{array}{ccc}-0.0815 & -0.0823 & -0.0804 \\ (0.0290) & (0.0291) & (0.0290) \\ ((1.0054)) & ((0.9783)) & ((0.8077))\end{array}$

5.51

15.47

5.56

$\begin{array}{ccc}0.01367 & 0.01325 & 0.01321 \\ (0.2591) & (0.2612) & (0.2631) \\ ((-16.7101))^{\mathrm{a}} & ((-16.5526))^{\mathrm{a}} & ((-16.4492))^{\mathrm{a}} \\ & & \\ 0.03509 & 0.03509 & 0.03497 \\ (0.0526) & (0.0527) & (0.0528) \\ ((-63.6381))^{\mathrm{a}} & ((-63.5438))^{\mathrm{a}} & ((-63.5011))^{\mathrm{a}}\end{array}$

(standard errors); ((t-statistics)); ${ }^{a}$ significant at the $1 \%$ level; ${ }^{b}$ significant at the $5 \%$ level. 
Table 5

Nonlinear Estimation: Heterogeneous Error Term

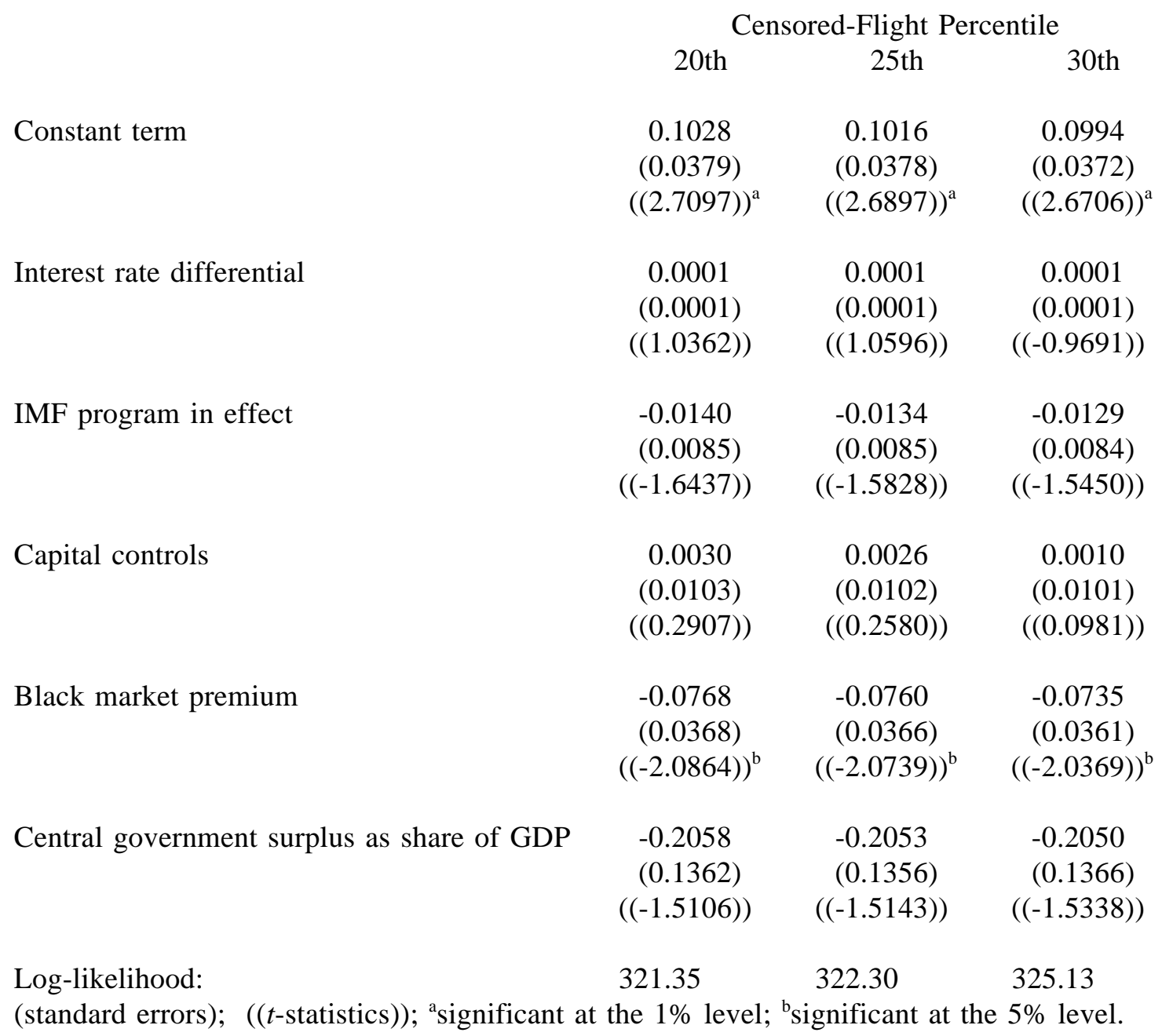


Table 6

Nonlinear Estimation: Heterogeneous Error Term

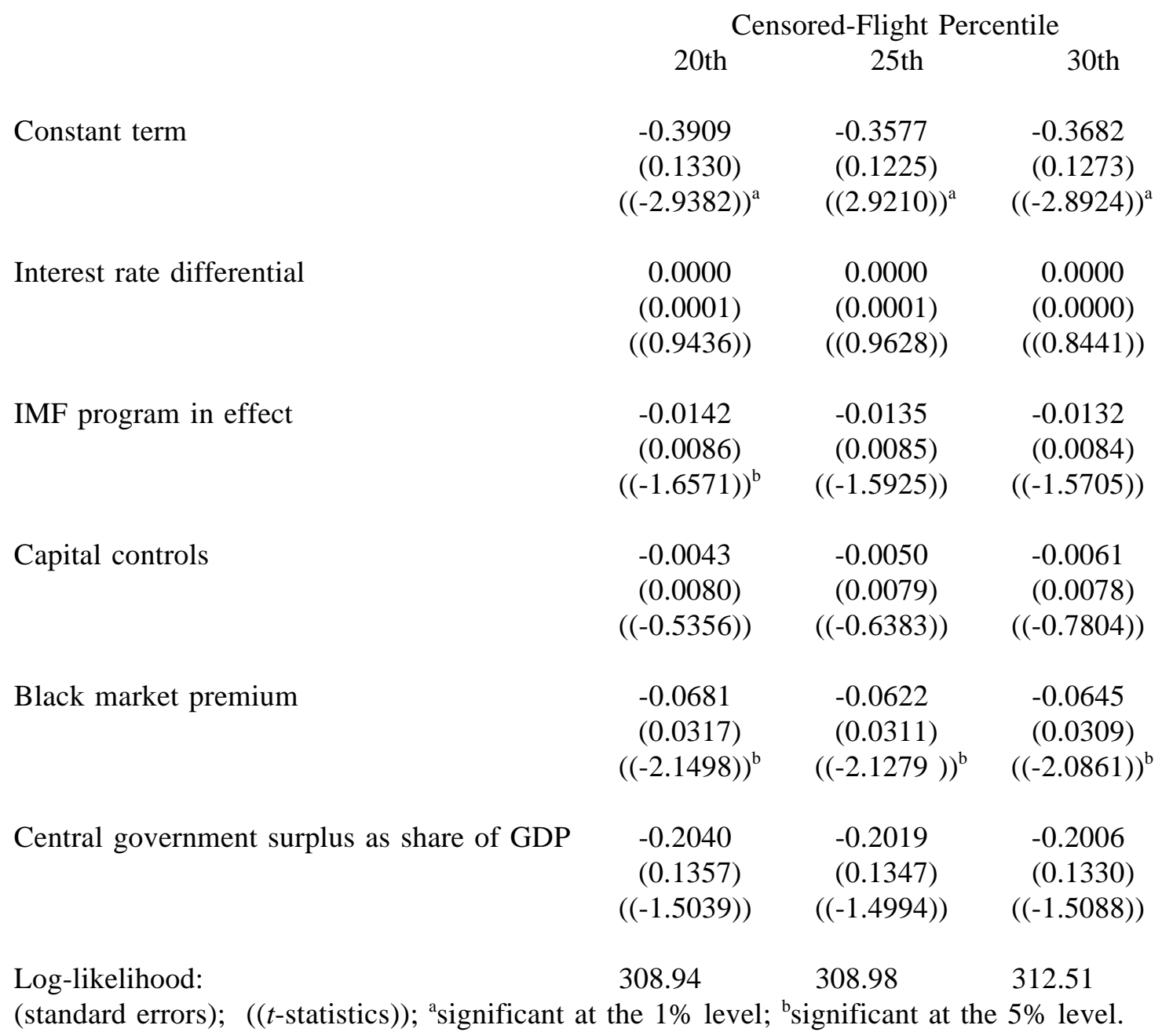




\section{References}

Agenor, Pierre-Richard (1990) "Stabilization Policies in Developing Countries with a Parallel Market for Foreign Exchange," IMF Staff Papers, Vol. 37, No.3, 560-592, September.

Amemiya, Takeshi (1985) Advanced Econometrics. Cambridge, MA: Harvard University Press.

Amemiya, Takeshi (1979) "The Estimation of a Simultaneous-Equation Tobit Model," International Economic Review, Vol. 20, No. 1, 169-181, February.

Bertola, Guiseppe and Ricardo J. Caballero (1992) "Irreversibility and Aggregate Investment," mimeo, May.

Buiter, Willem H. (1988) "Some Thoughts on the Role of Fiscal Policy in Stabilization and Structural Adjustment in Developing Countries," CEPR Discussion Paper no. 260.

Claessens, Stijn and David Naude (1993) "Recent Estimates of Capital Flight," World Bank Working Paper no. 1186.

Cuddington, J.T. (1986) "Capital Flight: Issues, Estimates and Explanations," Princeton Studies in Intemational Finance no. 58.

Cumby, R.E. and R.M. Levich (1987) "On the Definition and Magnitude of Recent Capital Flight," NBER Working Paper no. 2275.

Deppler, Michael and Martin Williamson (1987) "Capital Flight: Concepts, Measurement, and Issues," Staff Study: Research Department of the International Monetary Fund. Washington DC: International Monetary Fund.

Dooley, Michael P. (1988) "Capital Flight: A Response to Differences in Financial Risks," IMF Staff Papers, 422-436.

Dornbusch, Rudiger, et. al. (1983) "The Black Market for Dollars in Brazil," Quarterly Journal of Economics, 25-40.

Fishelson, Gideon (1988) "The Black Market for Foreign Exchange: An International Comparison," Economic Letters, 27, 67-71.

Griliches, Zvi and Jerry A. Hausman (1986) "Errors in Variables in Panel Data," Journal of Econometrics, 31, 93-118.

Hajivassiliou, Vassilis (1989) "Do Secondary Markets Believe in Life after Debt?," in Dealing with the Debt Crisis, eds., Ishrat Husain and Ishac Diwan. Washington DC: The World Bank.

Johnston, J. (1984) Econometric Methods. New York: McGraw Hill Book Company.

Judge, George G. et. al. (1985) The Theory and Practice of Econometrics. New York: John Wiley and Sons.

Khan, Moshin S. (1990) "The Macroeconomic Effects of Fund Supported Adjustment Programs," 
IMF Staff Papers, Vol. 37, No. 2, 195-231, June.

Kaufman, Daniel and Stephen A. O'Connell (1990) "The Macroeconomics of the Unofficial Foreign Exchange Market in Tanzania," mimeo, May.

Lessard, D.R. and J. Williamson (1987) Capital Flight and Third World Debt. Washington DC: Institute for International Economics.

Maddala, G.S. (1983) Limited-dependent and Qualitative Variables in Econometrics. Cambridge: Cambridge University Press.

Newey, Whitney K. (1987) "Efficient Estimation of Limited Dependent Variable Models with Endogenous Explanatory Variables," Journal of Econometrics, 36, 231-250.

Phylaktis, Kate (1992) "The Black Market for Dollars in Chile," Journal of Development Economics, 37, 155-172.

Rojas-Suarez, Liliana (1991) "Risk and Capital Flight in Developing Countries," IMF Occasional Working Paper no. 77: Determinants and Systemic Consequences of International Capital Flows.

Rosett, Richard N. (1959) "A Statistical Model of Friction in Economics," Econometrica, 27, 263267.

Roubini, Nouriel and Jeffrey Sachs (1989) "Political and Economic Determinants of Budget Deficits in the Industrial Democracies," European Economic Review, 33,903-938.

Schineller, Lisa (1993) "Hysteresis, Political Risk and International Capital Movements: Essays on Capital Flight," Department of Economics, Yale University, Ph.D. disseration, May.

Schineller, Lisa (1997) "An Econometric Model of Capital Flight from Developing Countries", International Finance Discussion Papers, Federal Reserve Board, Number 579.

Varman, Benu (1989) "Capital Flight - A Critique of Concepts and Measures including a case study of India and the Philippines," HWWA-Institut fur Wirtschaftsforschung, Verlag Weltarchiv, Hamburg, West Germany.

Varman, Benu and Wolfgang Schneider (1989) "Measuring Capital Flight: A Time Varying Regression Analysis, Universitat Kiel Discussion Paper No. 82/89, December. 